\title{
Nanomechanical Evaluation of Ultrathin Lubricant Films on Magnetic Disks by Atomic Force Microscopy
}

\author{
Shojiro Miyake ${ }^{1}$ and Mei Wang 2 \\ ${ }^{1}$ Department of Innovative System Engineering, \\ Nippon Institute of Technology, Saitama \\ ${ }^{2}$ Department of Research and Development, OSG Corporation, Aichi \\ Japan
}

\section{Introduction}

With the development of information technology, marked progress has been made in hard disks. To realize high-density memory, it is necessary to decrease the flying height between the head and disk. However, there is the possibility of head-crash in high-density magnetic systems because the flying height of the most recent hard disks is less than $10 \mathrm{~nm}$. Therefore, an extremely thin protective layer against wear and corrosion must now be applied to the magnetic head-disk interface (Miyake et al., 2002).

Sputtered carbon films with thicknesses as low as $10 \mathrm{~nm}$ are currently used as protective layers. Because the use of protective layers may lead to magnetic loss, their thickness must be decreased to $1-5 \mathrm{~nm}$, corresponding to approximately ten layers of atoms to decrease the effective gap at the interface between the magnetic head and disk. However, the thinner the protective layer, the more difficult the maintenance of its tribological durability. If a magnetic protective layer with a graded composition could be formed, it would effectively improve the tribological characteristics of discontinuous protective films. Although sputtered carbonaceous films are currently employed as magnetic disk protective layers (Kaneko et al., 1990; Miyake, 1994), the possibility of realizing carbon nitride $\mathrm{C}_{3} \mathrm{~N}_{4}$ (Cutinogco et al., 1996) has attracted interest, because the volumetric modulus of elasticity of $\mathrm{C}_{3} \mathrm{~N}_{4}$ has been theoretically predicted to exceed that of diamond (Liu \& Cohen, 1989). Amorphous nitrogen containing carbon films have been shown to have superior mechanical properties (Miyake et al., 1994, 1997).

Diamond-like carbon (DLC) films are currently employed as magnetic disk protective layers (Miyake et al., 1992, 1993; Miyake, 1994). A reduction in the effective clearance at the magnetic head-disk interface requires a reduction in the thickness of the protective film (Miyake, et al., 2005). That is, when considering a film of the above thickness, the corpuscular characteristics of atoms subjected to friction and wear should be taken into account. Nowadays, electron cyclotron resonance chemical vapor deposition (ECR-CVD) (Yamamoto et al., 2000) is used to deposit thin films, and filtered cathodic vacuum arc (FCVA) tetrahedral Amorphous Carbon (ta-C) (Hyodo et al., 2001; Robertson, 2008; Yamamoto et al., 2003) thin films are expected to be applied to magnetic disks. 
On the other hand, the tribological properties of lubricant and protective DLC systems play a very important role in the reliability of hard disks. A number of studies have been carried out to clarify the characteristics of lubricant and DLC systems (Saitoh \& Miyake, 2003; Saperstein \& Lin, 1990; Tani, 1999). Previous works on clarifying the optimal quantities of lubricant on a hard disk surface by scanning probe microscopy (SPM) have employed the force modulation method (Saitoh \& Miyake, 2003). On the surface of a hard disk, a low-lying part is defined as a valley and a hilltop part is defined as a hill. The hill and valley parts represent the surface roughness of the hard disk. The valley contains large quantities of lubricant, because $\tan \delta$ for the valley is larger than that for the hill (Saitoh \& Miyake, 2003).

Perfluoropolyether (PFPE) is employed as a lubricant in magnetic recording disk drives to improve tribological properties. An ultrathin PFPE lubricant film is particularly effective in decreasing the wear of the protective carbon layer due to sliding at the head-disk interface. The wear durability of the medium depends strongly on the retention and replenishment of the lubricant on the protective carbon surface. Both the retention and replenishment of lubricant are dependent on the interaction between the lubricant molecules and the carbon surface. A fundamental understanding of the lubricant-surface interactions in terms of their relationship to surface mobility is therefore required.

In this chapter, we firstly reported the method for evaluating the tribological properties of extremely thin protective nitrogen-containing carbon (C-N) films deposited on magnetic hard disks. The extremely thin C-N films with thicknesses of 3, 6 and 9 nm were prepared as a protective layer on CoCrTa magnetic disks by a complex treatment (Miyake et al., 2006). The bonding structure and composition of the films were studied by X-ray photoelectron spectroscopy (XPS). The nanohardness and elastic modulus of the films were measured by performing nanoindentation tests using atomic force microscopy (AFM). Wear tests were carried out to investigate the wear-resistance properties of the films.

Secondly, we reported the method for evaluating the nanometer-scale mechanical properties of extremely thin DLC films. The extremely thin DLC films were deposited by the FCVA and plasma chemical vapor deposition (p-CVD) methods (Miyake et al., 2009). Nanoindentation hardness and nanowear resistance were evaluated by AFM. The nanoindentation hardnesses of 100-nm-thick DLC films deposited by FCVA and p-CVD were 57 and $25 \mathrm{GPa}$, respectively. The nanowear test by AFM clarified the mechanical properties of the extremely thin DLC films.

Third, we reported the method for evaluating the microtribological properties of heat-treated hard disk evaluated by force modulation. The durability of PFPE lubricant and heat-treated perpendicular hard disks was evaluated. With regard to the heat treated perpendicular hard disks, their microtribological properties such as hardness, storage modulus, loss modulus and $\tan \delta$ were evaluated by SPM. In a quasi-static nanoindentation hardness test, it was observed that nanoindentation hardness in the valleys was higher than that on the hills, and the hardness of the hard disk was increased by heat treatment. Consistent with the results of quasi-static nanoindentation in the dynamic nanoindentation test, the storage modulus and loss modulus were increased by heat treatment. Moreover, $\tan \delta$ also increased as clarified by the evaluation of viscoelastic properties. On the other hand, regarding the microwear properties, the wear depth of the heat-treated disk and its wear volume were decreased by heat treatment, corresponding to the result of quasi-static nanoindentation. 


\section{Methods for evaluating nanomechanical properties of extremely thin films}

\subsection{Evaluation of nanoindentation hardness}

To evaluate nanometer-scale deformation properties, the nanohardness and elastic modulus of all films were measured using a Hysitron Triboscope ${ }^{\circledR}$ nanomechanical testing system (Doerner et al., 1986; Farhat et al., 1997; Miyake, 2003). A total of ten indentations were performed for each sample and the mean values and standard deviation of the hardness and elastic modulus were computed; the results are provided later in the chapter. The diamond triangular pyramid (Berkovich-type) indenter that was used had an approximate tip radius of $50 \mathrm{~nm}$ and an indent angle of $120^{\circ}$. The hardnesses of the films were determined using the relation $\mathrm{H}=P / \mathrm{A}_{\max }$, where $\mathrm{A}_{\max }$ is the area of contact, $\mathrm{A}_{\max }=k \cdot h_{p}{ }^{2}$ (the constant $k$ for the Berkovich indenter was 24.5), $h_{p}$ is the plastic penetration depth and $P$ is the indenter load (Bhushan, 1995; Farhat et al., 1997; Miyake, 2003). The indentation was performed under a load of $100 \mu \mathrm{N}$. As shown in Fig. 1, from the load-displacement curves and the tangent of the unloading curves, the depth of plastic deformation can be evaluated. The deformation energy during indentation was analyzed. The total deformation energy including storage and dissipated energies was calculated as the integral of the loading curve. The storage energy was calculated as the integral of the unloading curve and the dissipated energy was evaluated as the total energy minus the storage energy (Farhat et al., 1997; Miyake, 2003). The modulus of dissipation was calculated as the dissipated energy divided by the total energy.

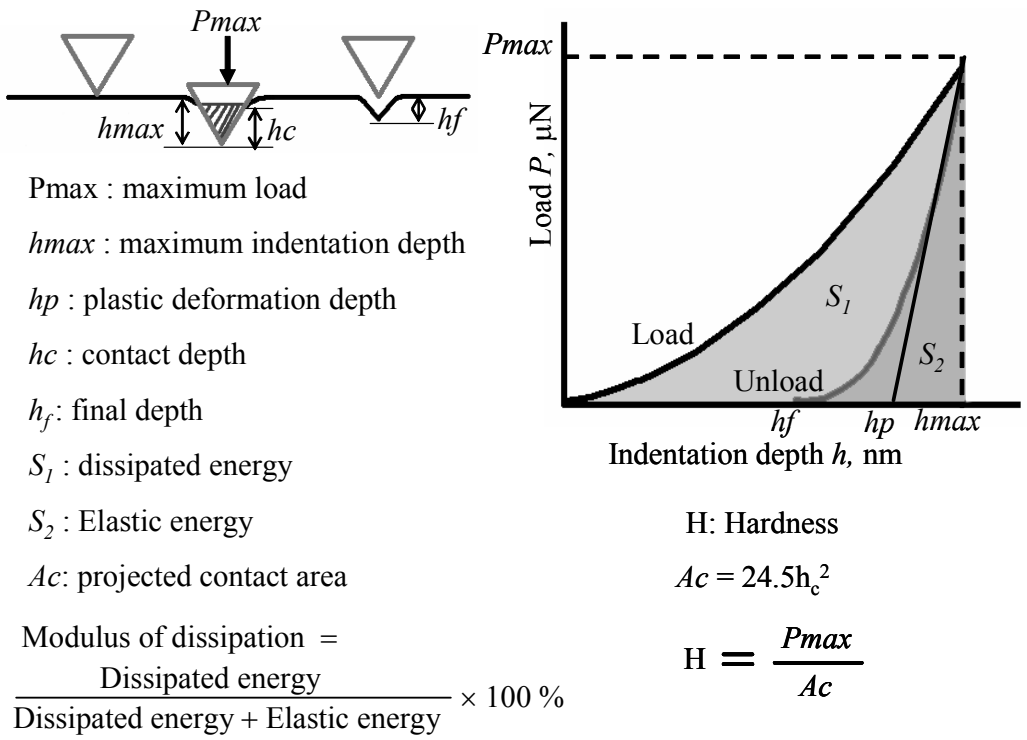

Fig. 1. Method of evaluating of nanoindentation hardness.

\subsection{Evaluation of nanometer-scale wear resistance}

The nanometer-scale wear resistance of the films was investigated by AFM using a diamond tip (Miyake et al., 1991). The dependence of the wear resistance of the C-N films on the 
number of scanning cycles, the dependence of the wear resistance of the DLC films on the film thickness, and the dependence of the wear volume of the PFPE lubricant on the applied load were evaluated, where the wear depths of the extremely thin $\mathrm{CN}$ films were evaluated by applying a load of $15 \mu \mathrm{N}$ for 1, 5 and 10 scanning cycles, the nanowear depths of the 0.8-, 1and 2-, 5- and 100-nm-thick ECR-CVD-DLC and FCVA-DLC films were evaluated by applying a load of $10 \mu \mathrm{N}$ for 20 sliding cycles of tip scanning and the wear volumes of the PFPE lubricant films were evaluated by scanning a wear area of $500 \times 500 \mathrm{~nm}^{2}$ using a Berkovich type diamond tip with a radius of curvature of $200 \mathrm{~nm}$ under loads of $10-80 \mu \mathrm{N}$. As shown in Fig. 2, a triangular pyramid Berkovich diamond indenter was used with loads of $10 \mu \mathrm{N}$ for the DLC films, $15 \mu \mathrm{N}$ for the C-N films and $10-80 \mu \mathrm{N}$ for the PFPE lubricant films in the wear tests, and the radius of the indenter tip was approximately $200 \mathrm{~nm}$. During the experiment, the wear test area was $500 \mathrm{~nm} \times 500 \mathrm{~nm}$ and the observed areas were $1000 \mathrm{~nm} \times 1000 \mathrm{~nm}$ and/or 2000 $\mathrm{nm} \times 2000 \mathrm{~nm}$, which were larger than the sliding area (Miyake et al., 1994, 2006).

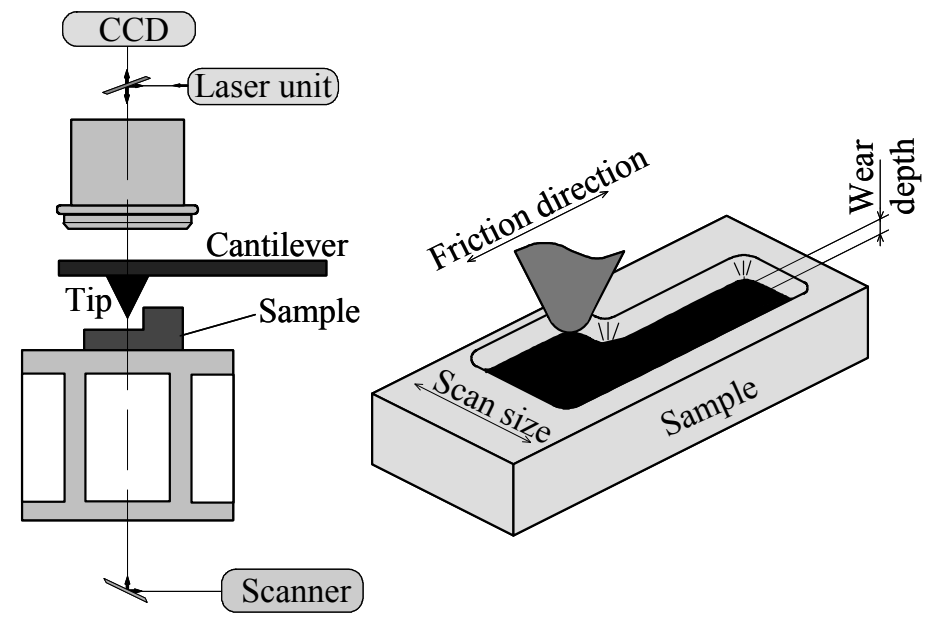

Fig. 2. Microwear test by atomic force microscopy (AFM).

\subsection{Evaluation of viscoelastic properties}

Viscoelastic properties were evaluated by the force modulation method of SPM as shown in Fig. 3 (Asif et al. 1999). This apparatus was added to nanoindentation system along with a lock-in amplifier. The Berkovich-type diamond indenter was vibrated in the vertical direction in the test. Phase lag and displacement were evaluated from the response of the tip indenter, which contained a transducer controller. Viscoelastic properties such as storage modulus, loss modulus and $\tan \delta$ were analyzed by a computer. In the test the load was increased from $10 \mu \mathrm{N}$ to $50 \mu \mathrm{N}$, the frequency was $300 \mathrm{~Hz}$ and the load amplitude was 5.0 $\mu \mathrm{N}$. Table 1 shows the test conditions for the viscoelastic evaluation. To examine the existence of PFPE, test points were located on both a hill and a valley, as shown in Fig. 4. The hill and valley parts represent the surface roughness of a hard disk, the surfaces of hard disks were observed before the evaluation of viscoelastic properties to measure the amplitudes of the hill and valley regions. To determine the motion of PFPE on the wear test area, viscoelastic properties were evaluated after the microwear test. 


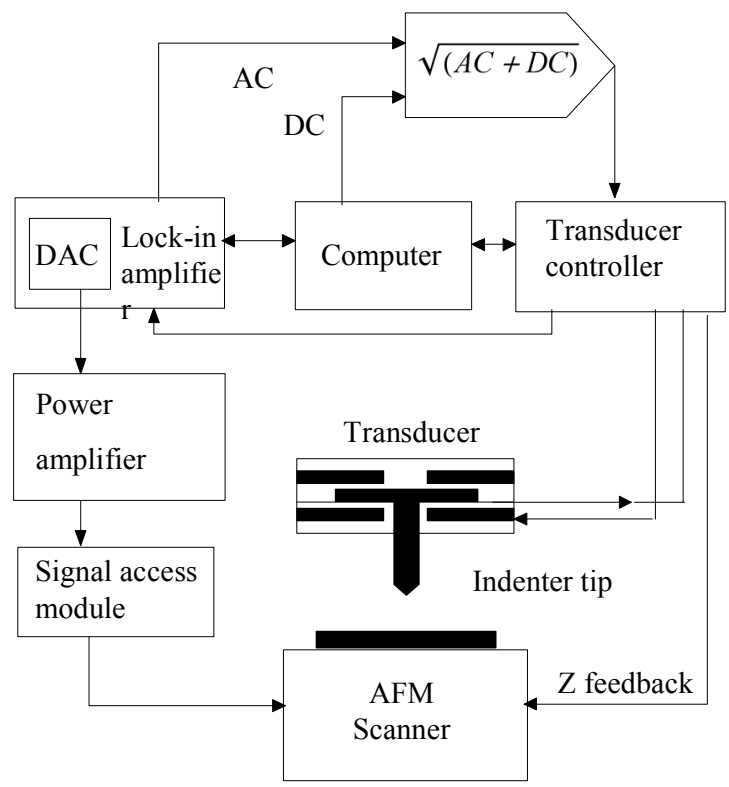

Fig. 3. Schematic illustration of nanoindentation system with lock-in amplifier.

\begin{tabular}{l|l}
\hline Specimen & Heat treated and non-treated perpendicular type hard \\
Test temprature & disk \\
Humidity & $30-25$ centigrade degree \\
Tip & Berkobitch diamond $\mathrm{r}=200 \mathrm{~nm}$ \\
Load & $10-50 \mu \mathrm{N}$ \\
Load amplitude & $5.0 \mu \mathrm{N}$ \\
Frequency & $300 \mathrm{~Hz}$ \\
\hline
\end{tabular}

Table 1. The evaluation conditions for the viscoelastic properties.

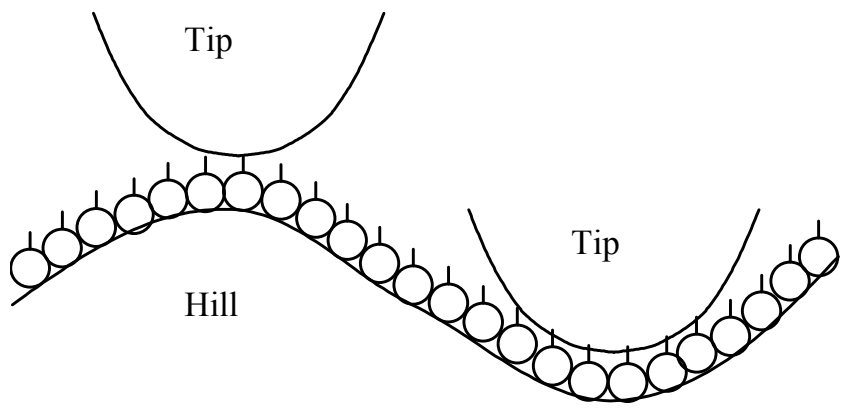

Valley

Fig. 4. Schematic illustration of evaluation of viscoelastic properties of hill and valley. 


\section{Nanoscale mechanical and tribological properties of extremely thin films}

\subsection{Mechanical properties of extremely thin $\mathrm{C}-\mathrm{N}$ films}

\subsubsection{XPS evaluation of modified surface of $\mathrm{C}-\mathrm{N}$ films}

CoCrTa magnetic disks were used as substrates for the fabrication of extremely thin C-N films. The extremely thin C-N films were deposited on the CoCrTa magnetic disks in the sputtering chamber of radio frequency (RF) reactive sputtering equipment, which was able to supply an RF power of $13.56 \mathrm{MHz}$ to both a target and a substrate. Two sets of C-N thin films were prepared, one set by RF reactive sputtering and the other set by a complex treatment (Miyake et al., 2006). The complex treatment, which involves plasma irradiation (plasma-irradiated) and the deposition of C-N film, where the substrate was pretreated by plasma irradiation and then treated by the deposition of a $\mathrm{C}-\mathrm{N}$ film by $\mathrm{RF}$ reactive sputtering (Miyake et al., 2006) was carried out to form complex C-N films. The depositions of C-N and complex C-N films were performed by supplying $\mathrm{N}_{2}$ or $\mathrm{N}_{2}+\mathrm{He}$ (helium) under a pressure of $7 \times 10^{-2}$ Torr and RF electric powers of $25 \mathrm{~W}$ on the substrate side and $300 \mathrm{~W}$ on the target side to deposit a nitrogen-containing carbon film with high wear resistance as a protective film (Cutinogco et al., 1996; Liu \& Cohe, 1990; Miyake et al., 1994; White et al, 1996). The thickness of the C-N films was determined by controlling the deposition time. The addition of He to the plasma atmosphere was to enhance the excitation process (Miyake \& Wang, 2004; Sugimoto \& Miyake, 1989).

Both XPS and Auger electron spectroscopy (AES) were used to examine the elemental composition and bonding of the film. Figure 5 shows XPS spectra of carbon (C) and C-N films. A binding energy (BE) of $284.6 \mathrm{eV}$ for the $\mathrm{C} 1 \mathrm{~s}$ photoelectron peak in the XPS spectrum of the carbon film was obtained (Fig. 5(a)). A conspicuous shoulder in the XPS spectra on the high-energy side was observed in the XPS measurement of the C-N film (Fig. 5(b)), indicating the existence of C-N bonds (Miyake et al., 2006).

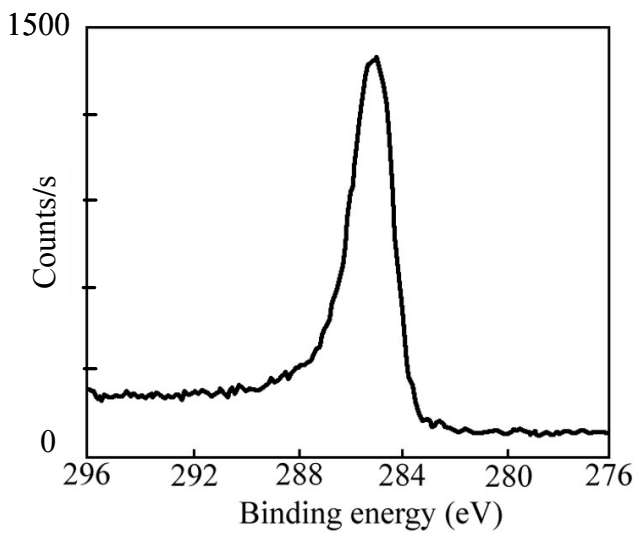

(a)

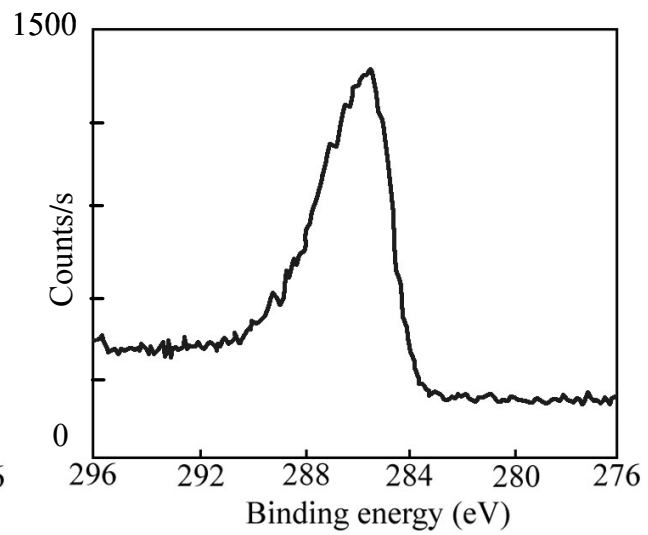

(b)

(a) XPS of carbon film

(b) XPS of C-N film deposited with complex treatment

Fig. 5. XPS spectra of carbon film and C-N film deposited by complex treatment. 


\subsubsection{Nanoindentation hardness of $\mathrm{C}-\mathrm{N}$ films}

The indentation curves for the untreated sample and the C-N and complex C-N films deposited in an atmosphere of $\mathrm{N}_{2}$ or $\mathrm{N}_{2}+\mathrm{He}$ were obtained at a maximum applied load of $100 \mu \mathrm{N}$. In these tests, nanoindentation was performed perpendicular to the plane of the coatings and each curve represents an average of ten measurements taken for each specimen. As shown in Figs. 6(a) and 6(b), the maximum depths $\left(h_{m}\right)$ of the 3-, 6- and 9-nmthick complex C-N films deposited in $\mathrm{N}_{2}+$ He were 5.2, 5.3 and $5.0 \mathrm{~nm}$ with residual depths of $0.1,0.2$ and $0.1 \mathrm{~nm}$, respectively. In the case of 3-, 6- and 9-nm-thick C-N films, the maximum depths were 8.5, 8.1 and $7.1 \mathrm{~nm}$ and the residual depths were $3.8,2.9$ and $3.3 \mathrm{~nm}$, respectively, indicating that more plastic deformation occurred in these films.

The hardness of the C-N and complex C-N films at the maximum applied load of $100 \mu \mathrm{N}$ is plotted in Figs. 7(a) and 7(b). The hardness of the complex C-N films is greater than that of the C-N films. Moreover, the complex C-N films deposited in $\mathrm{N}_{2}+\mathrm{He}$ exhibit the greatest hardness. The average hardness values of the complex 3-, 6- and 9-nm-thick C-N films deposited in $\mathrm{N}_{2}$ are 62.6, 31.9 and $34.1 \mathrm{GPa}$, whereas those of the 3-, 6- and 9-nm-thick complex C-N films deposited in $\mathrm{N}_{2}+\mathrm{He}$ were $67.8,63.8$ and $63.8 \mathrm{GPa}$, respectively.

Figures $8(\mathrm{a})$ and $8(\mathrm{~b})$ show the deformation energies of the C-N and complex C-N films. The deformation energies of the films deposited in $\mathrm{N}_{2}+\mathrm{He}$ were lower than those of the films deposited in $\mathrm{N}_{2}$. Furthermore, the dissipated energy of the complex C-N films significantly decreased with decreasing film thickness. It is considered that the elastic-plastic property of the disks was improved by the complex treatment involving He addition, which explains why the residual depth of the 3-nm-thick complex film was very small, the surface was restored to the previous position to its previous position after unloading.

Figure 9 shows the modulus of dissipation as a function of nanoindentation hardness. As shown in Fig. 9(a), the modulus of dissipation of the untreated sample was $90.7 \%$ with a hardness of 15.6 GPa. The moduli of dissipation of the 3-, 6- and 9-nm-thick complex C-N films deposited in $\mathrm{N}_{2}$ were $25.0 \%, 39.9 \%$ and $52.8 \%$, with hardnesses of $62.6,31.9$ and 34.1 GPa, respectively. However, as shown in Fig. 9(b), the moduli of dissipation of the 3-, 6- and 9-nm-thick complex C-N films deposited in $\mathrm{N}_{2}+$ He were only $0 \%, 8.3 \%$ and $9 \%$ with hardnesses of $67.8,63.8$ and $63.8 \mathrm{GPa}$, respectively. The 3-nm-thick complex C-N film had a small modulus of dissipation and a high hardness compared with the other films.

The method most widely used to determine the hardness of materials is the quasi-static indentation method. Since indentation hardness is essentially a measure of the plastic deformation properties of materials and depends only to a secondary extent on their elastic properties, the elastic-plastic deformation behavior of the films during indentation can be observed to study the nanomechanical properties of a topmost coating as thin as the monolayer of a substrate. In this study we considered the measured indentation hardness as a composite hardness that is affected by the type of substrate used. Although this composite hardness is derived from the impact with the substrate and cannot be regarded as an absolute hardness value for films, it can be used to investigate the plastic deformation of a topmost coating and a substrate by measuring comparative composite hardness values. For this reason, we analyzed the elastic-plastic deformation energies of the films to further understand their deformation properties. Although at higher indentation depths, the composite hardness of a film and a substrate changes with indentation depth, it is thought 


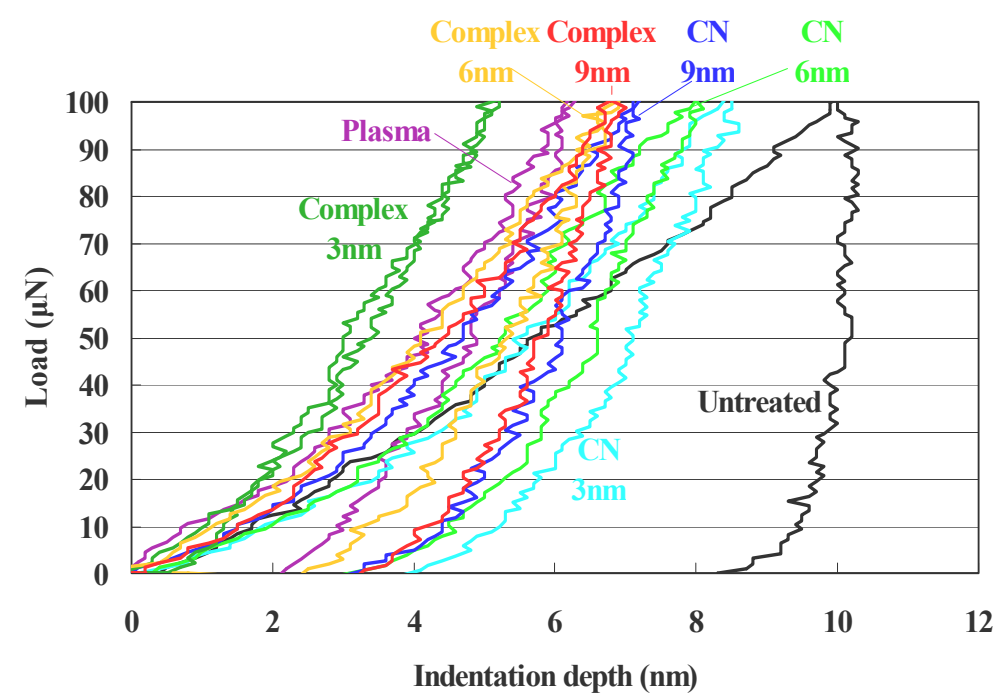

(a) Nanoindentation curves of C-N films deposited in $\mathrm{N}_{2}$

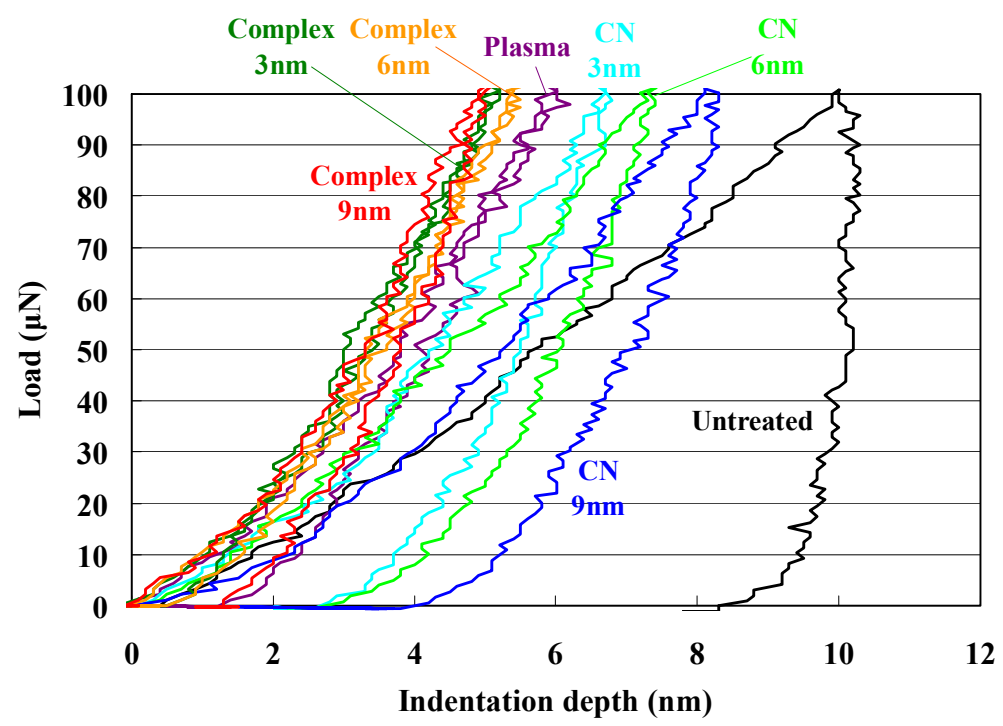

(b) Nanoindentation curves of C-N films deposited in $\mathrm{N}_{2}+\mathrm{He}$

Fig. 6. Load and displacement curves of untreated, plasma-irradiated, C-N and complex C$\mathrm{N}$ films deposited in $\mathrm{N}_{2}$ and $\mathrm{N}_{2}+\mathrm{He}$ at $100 \mu \mathrm{N}$ peak load.

that composite hardness is mainly determined by the topmost film on the substrate. Therefore, the results of the indentation tests also show that the complex C-N films had higher indentation hardness than the other films as well as good elastic-plastic deformation properties. 


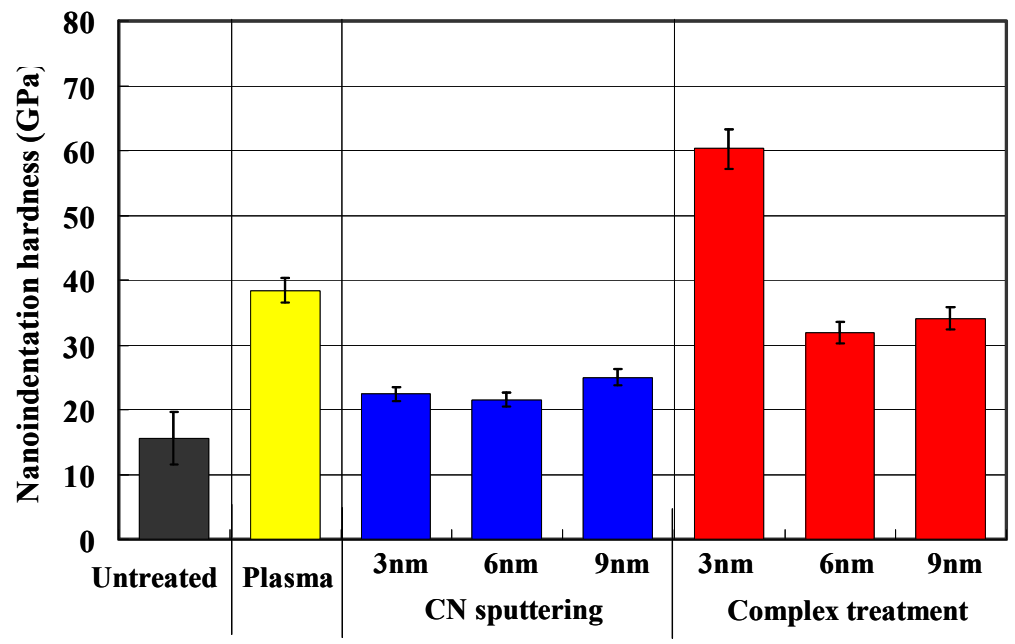

(a) Nanoindentation hardness of untreated and C-N films deposited in $\mathrm{N}_{2}$

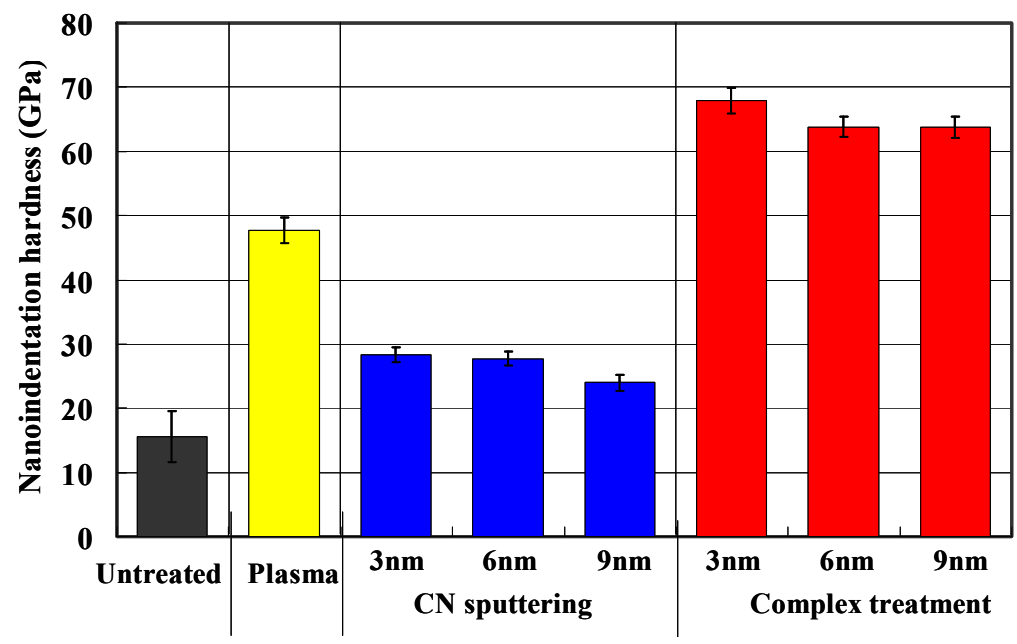

(b) Nanoindentation hardness of untreated and C-N films deposited in $\mathrm{N}_{2}+\mathrm{He}$

Fig. 7. Nanoindentation hardness of untreated, plasma-irradiated, C-N and complex C-N films deposited in $\mathrm{N}_{2}$ and $\mathrm{N}_{2}+\mathrm{He}$. 


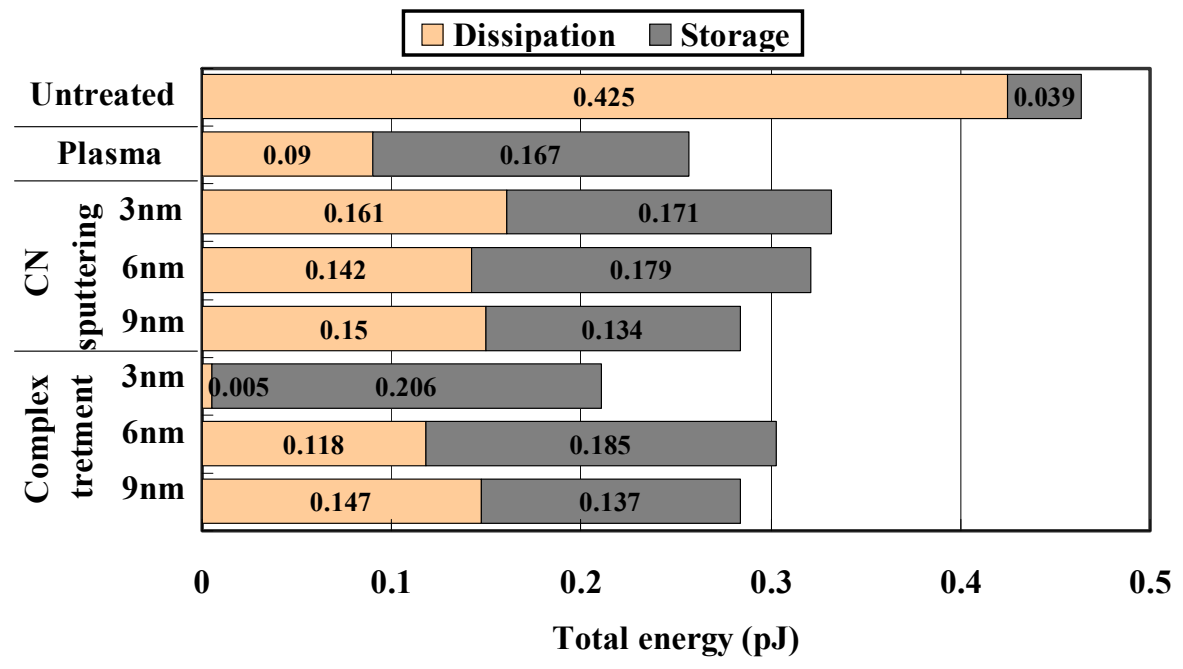

(a) C-N films deposited in $\mathrm{N}_{2}$

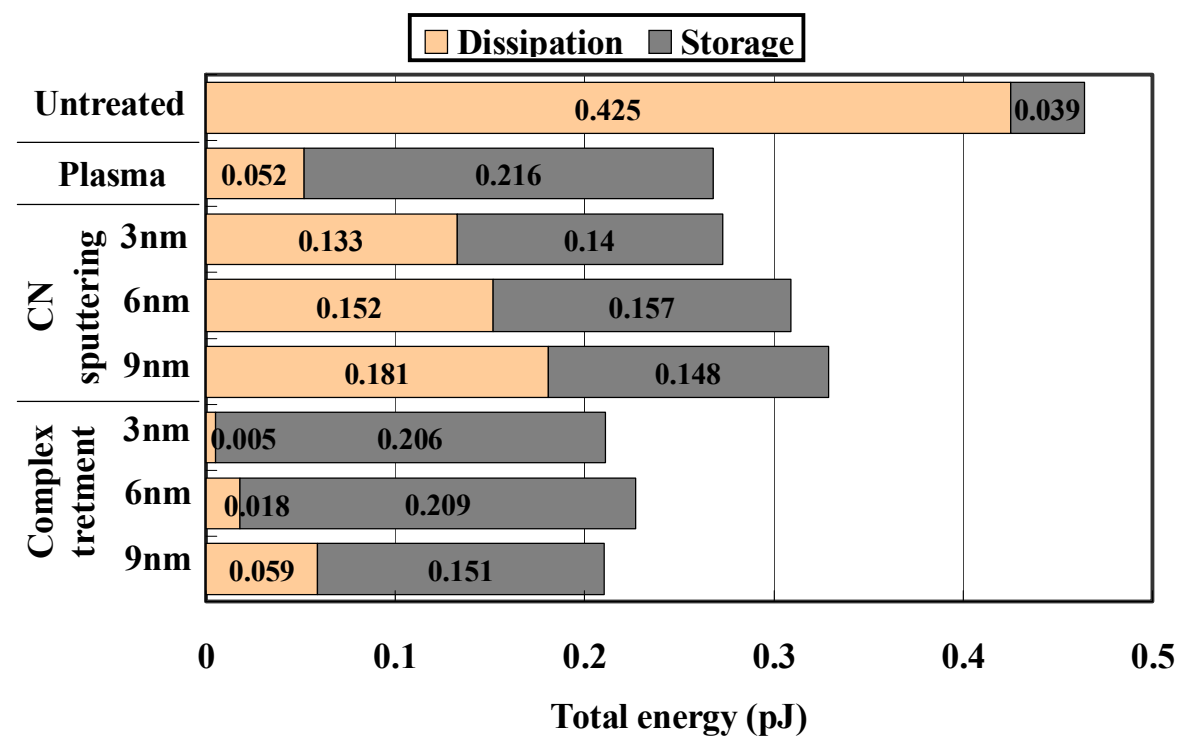

(b) C-N films deposited in $\mathrm{N}_{2}$ and $\mathrm{N}_{2}+\mathrm{He}$.

Fig. 8. Measured dissipation and storage energies of untreated, plasma-irradiated, $\mathrm{C}-\mathrm{N}$ and complex C-N films deposited in $\mathrm{N}_{2}$ and $\mathrm{N}_{2}+\mathrm{He}$. 


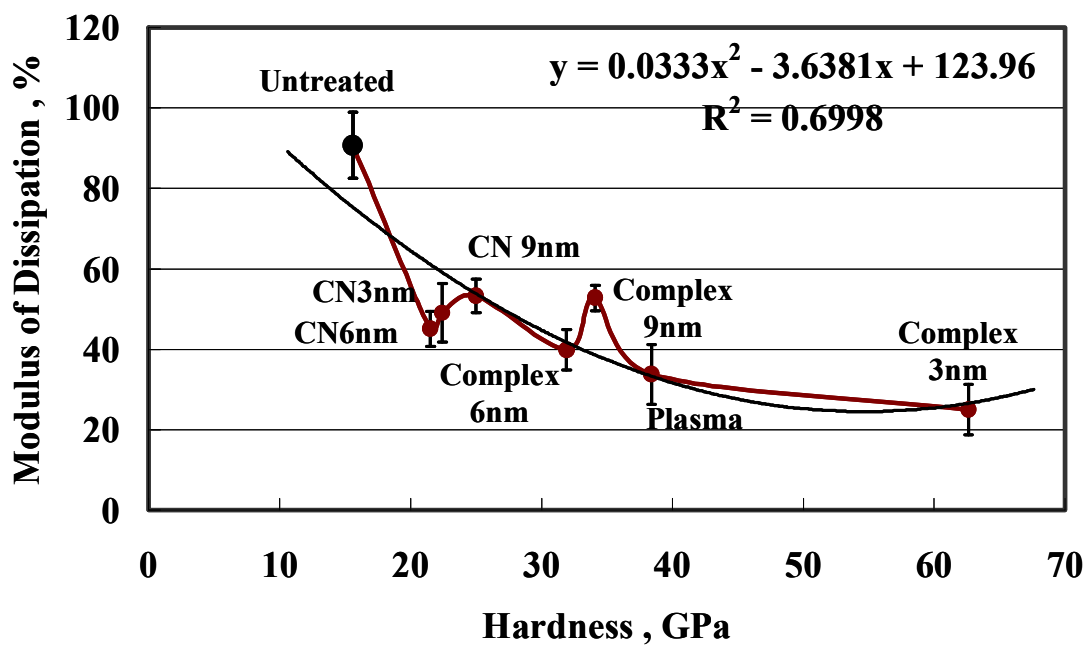

(a) C-N films deposited in $\mathrm{N}_{2}$

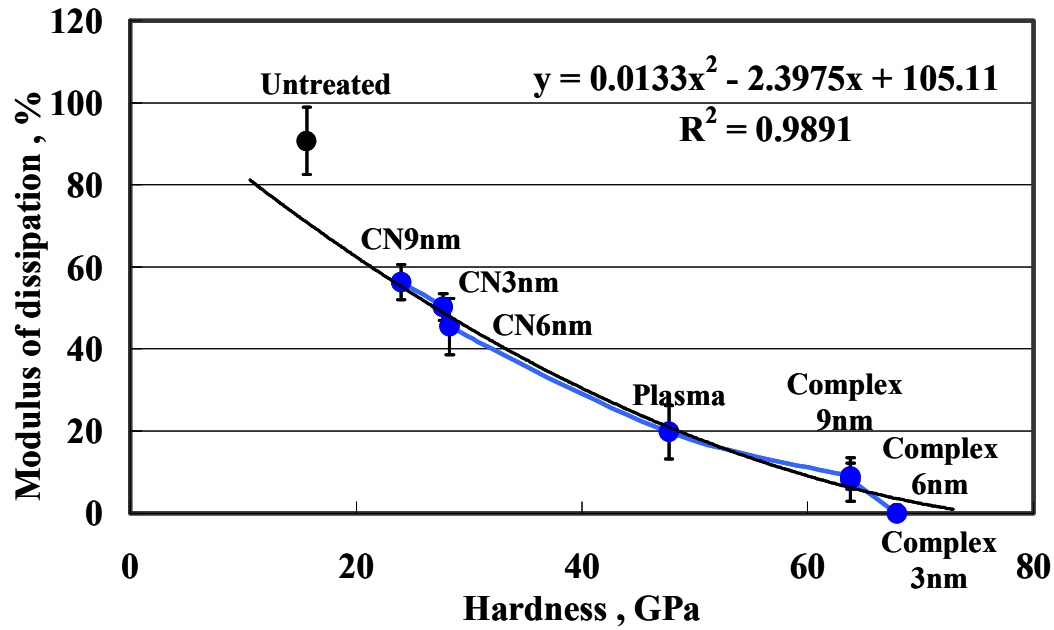

(b) C-N films deposited in $\mathrm{N}_{2}$ and $\mathrm{N}_{2}+\mathrm{He}$.

Fig. 9. Modulus of dissipation vs indentation hardness of untreated, plasma-irradiated, C-N and complex C-N films deposited in $\mathrm{N}_{2}$ and $\mathrm{N}_{2}+\mathrm{He}$.

\subsubsection{Microwear test for $\mathrm{C}-\mathrm{N}$ films}

Figures 10 and 11 show the wear depth dependence of the films on the number of scanning cycles. Wear tests were performed by applying a load of $15 \mu \mathrm{N}$ for 1,5 and 10 scanning cycles. The results indicate that the wear resistance of the disks was improved by the C-N and complex C-N film coatings. In addition, the wear resistance of the films deposited in $\mathrm{N}_{2}+\mathrm{He}$ was greater than that of the films deposited in $\mathrm{N}_{2}$. The wear of the 3-nm-thick complex C-N film deposited in $\mathrm{N}_{2}+\mathrm{He}$ was negligible compared with that of the other films. 


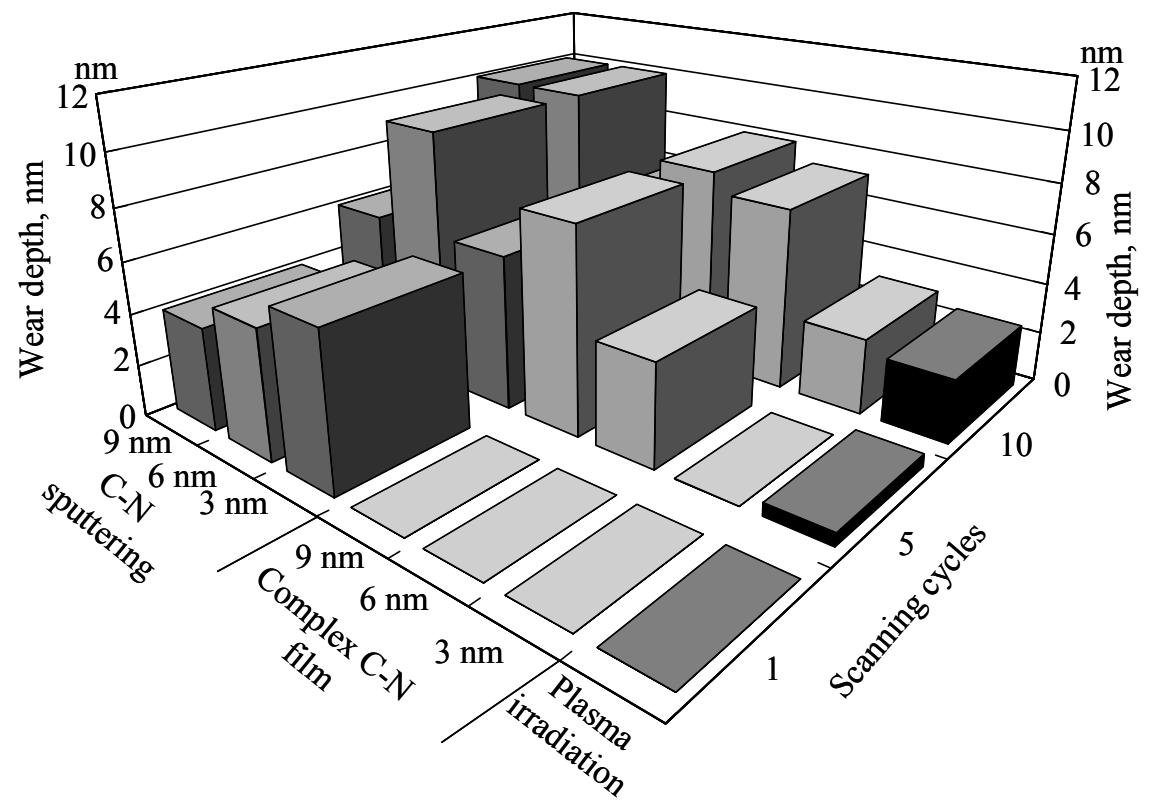

Fig. 10. Microwear dependence on number of scanning cycles for plasma-irradiated, C-N and complex C-N films deposited in $\mathrm{N}_{2}$.

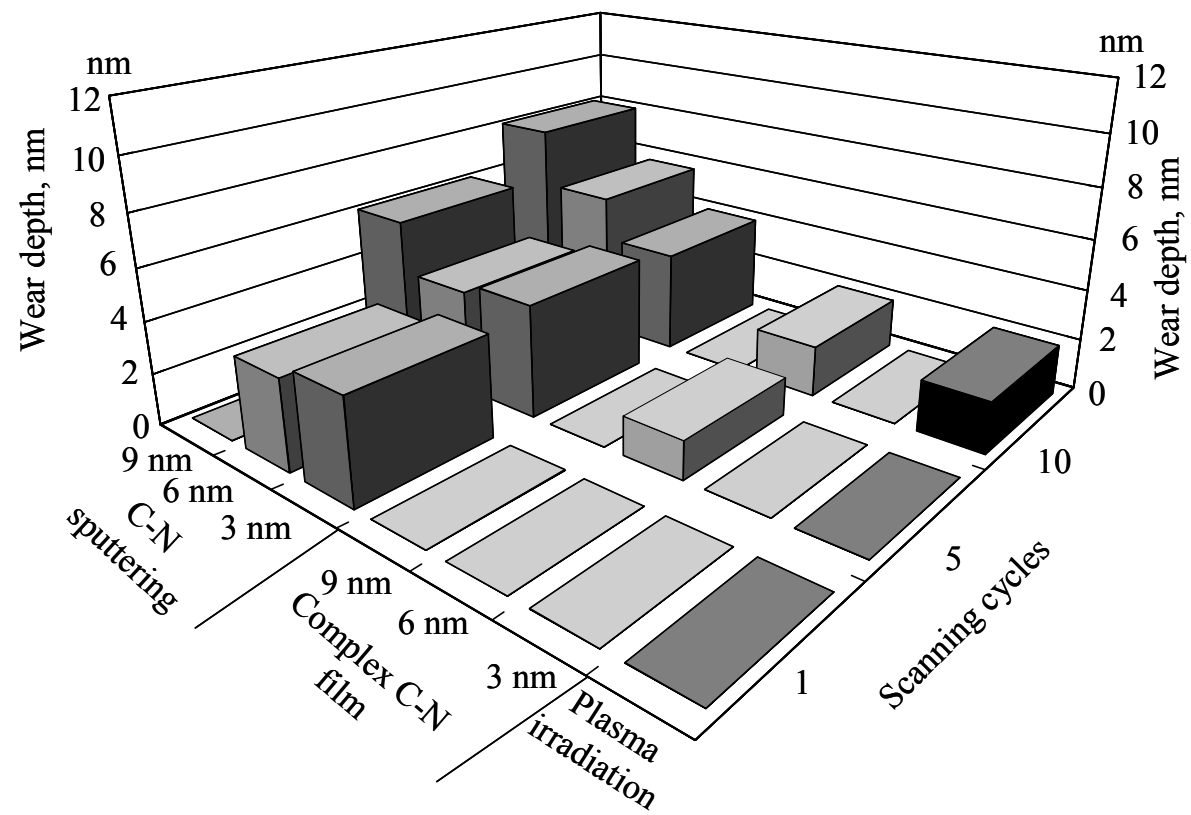

Fig. 11. Microwear dependence on number of scanning cycles for plasma-irradiated, C-N and complex C-N films deposited in $\mathrm{N}_{2}+\mathrm{He}$. 
Figures 12 and 13 show cross-sectional profiles of the wear marks generated on the plasmairradiated substrate and the substrates coated with 3-nm-thick C-N and complex C-N films. The normal force used for the image traces was $2 \mathrm{nN}$ and the load used for the wear test was $10 \mu \mathrm{N}$. The results show that wear was $2.5 \mathrm{~nm}$ deep for the plasma-irradiated sample, 6.0 $\mathrm{nm}$ for the C-N film and $3.0 \mathrm{~nm}$ for the complex C-N film deposited in $\mathrm{N}_{2}$. In the case of the films deposited in $\mathrm{N}_{2}+\mathrm{He}$, the wear was significantly lower, the wear was $2.0 \mathrm{~nm}$ deep for the plasma-irradiated sample, $4 \mathrm{~nm}$ for the C-N film and $0 \mathrm{~nm}$ for the complex C-N film. In addition to high indentation hardness, the C-N film exhibited excellent wear resistance owing to the plasma irradiation treatment in the presence of He. It is considered that the extremely thin $\mathrm{C}-\mathrm{N}$ film had superior wear resistance because of its graded composition.

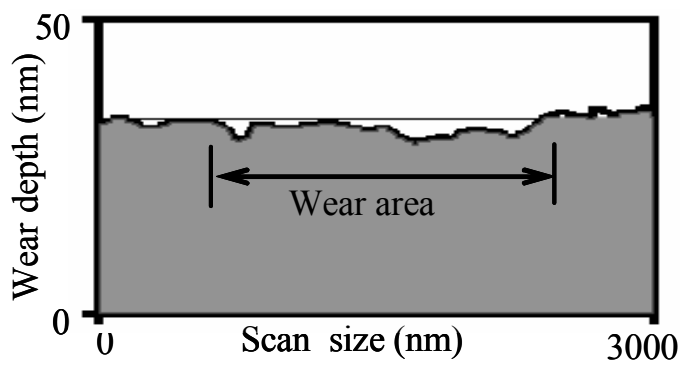

(a) Nitrogen plasma irradiation (wear depth $2.5 \mathrm{~nm}$ )

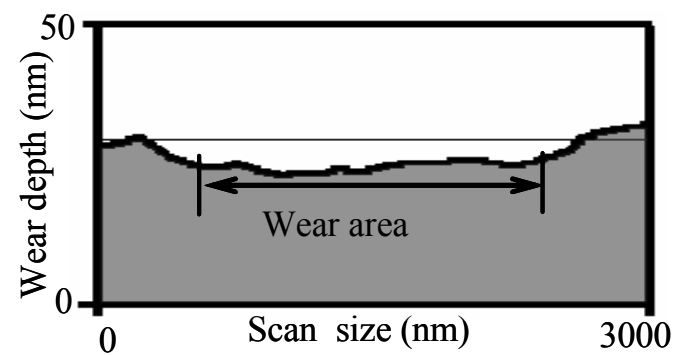

(b) C-N sputtering (wear depth $6.0 \mathrm{~nm}$ )

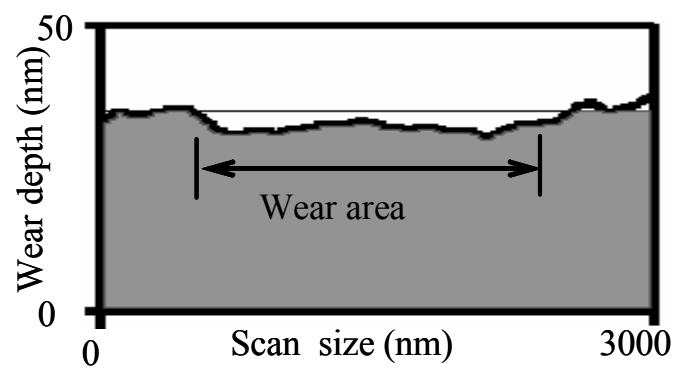

(c) Complex C-N film (wear depth $3.0 \mathrm{~nm}$ )

Fig. 12. Cross-sectional profiles of microwear of plasma-irradiated, $3 \mathrm{~nm} \mathrm{C-N}$ and complex C-N films deposited in $\mathrm{N}_{2}$. 


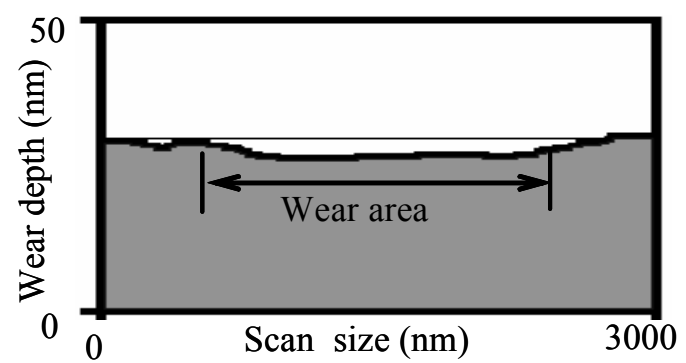

(a) Nitrogen plasma irradiation (wear depth $2.0 \mathrm{~nm}$ )

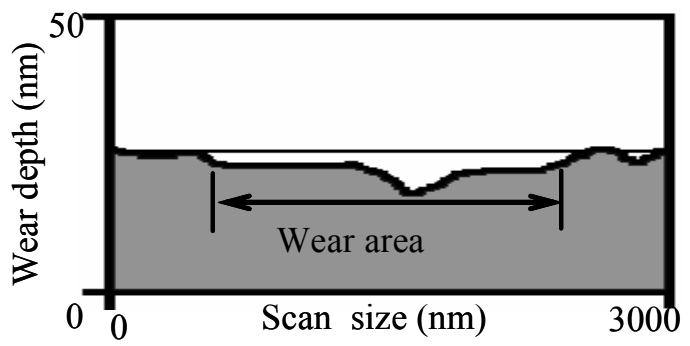

(b) C-N sputtering (wear depth $4.0 \mathrm{~nm}$ )

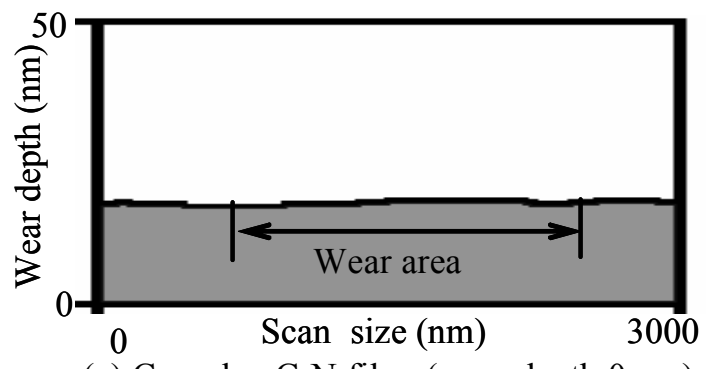

(c) Complex C-N film (wear depth $0 \mathrm{~nm}$ )

Fig. 13. Cross-sectional profiles of microwear of plasma-irradiated, $3 \mathrm{~nm} \mathrm{C-N}$ and complex C-N films deposited in $\mathrm{N}_{2}+\mathrm{He}$.

\subsection{Nanometer-scale mechanical properties of extremely thin protective DLC films}

\subsubsection{Surface analysis of DLC films}

Extremely thin protective DLC films were deposited on Si (100) wafers by FCVA (ta-C) and ECR-CVD (Hyodo et al., 2001; Miyake et al., 2009; Robertson, 2008; Yamamoto et al., 2000, 2003). The target thicknesses of films were $0.8,1.0,2.0,5.0$, and $100 \mathrm{~nm}$, where the film thickness was adjusted by changing the deposition time. The properties of these DLC films such as their structure, composition and actual thickness were evaluated using Raman spectroscopy, transmission electron microscopy (TEM) and AES (Miyake et al., 2009). 


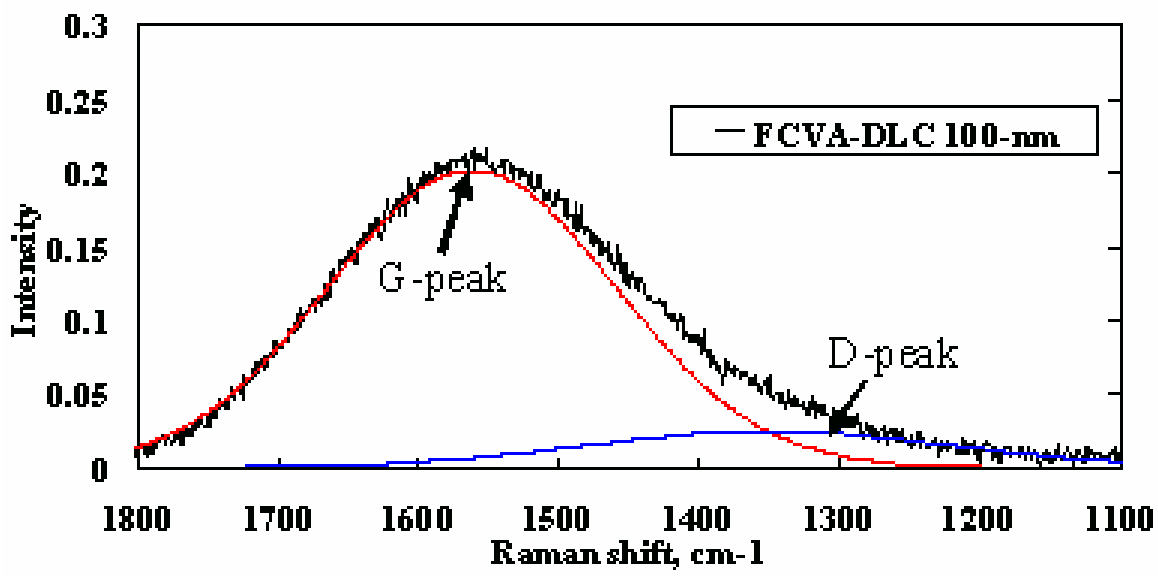

(a) FCVA-DLC 100nm

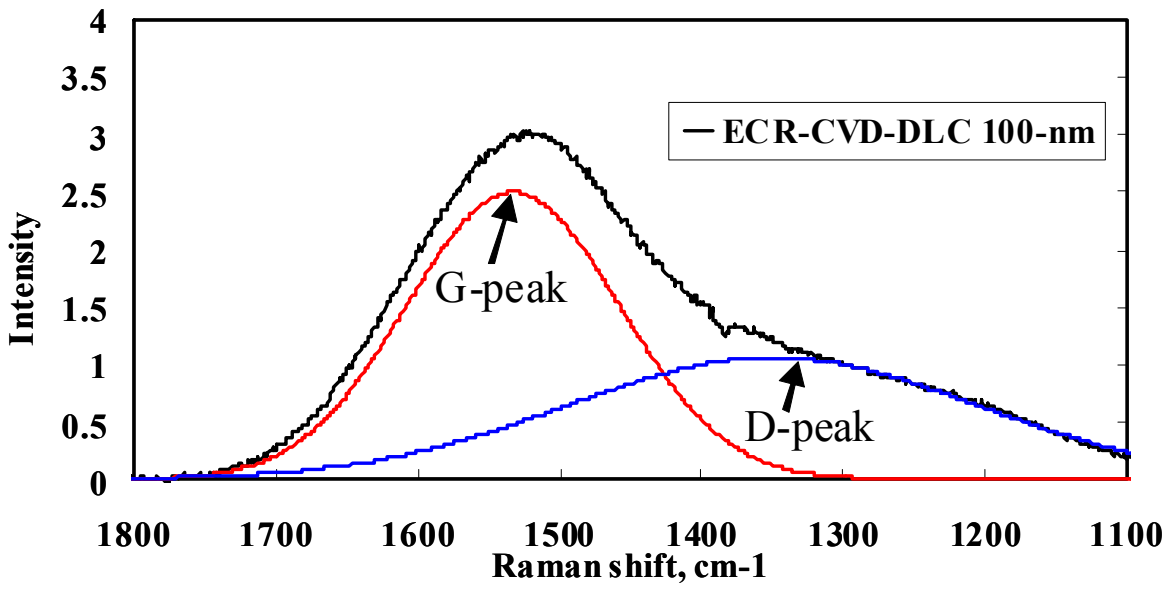

(b) ECR-CVD-DLC $100 \mathrm{~nm}$

Fig. 14. Raman spectra of (a) 100-nm-thick FCVA-DLC and (b) ECR-CVD-DLC films.

Figure 14 shows the Raman spectra of DLC films with a thickness of $100 \mathrm{~nm}$ prepared by FCVA and ECR-CVD. The spectra show that the FCVA-DLC (ta-C) film contained a large number of $\mathrm{sp}^{3}$ bonds than the ECR-CVD (a-CH) film (Ferrari, 2002; Lemoinea et al., 2007; Miyake et al., 2009).

From the cross-sectional TEM images and AES depth profiles of FCVA and ECR-CVD-DLC films of various thicknesses, the actual thicknesses of the extremely thin films were evaluated. The AES spectra of the top surfaces of the 1-nm-thick DLC films are shown in Fig. 15. For these films, according to the AES analysis of the surface, $C$ is the main component with small amounts of $\mathrm{O}$ and $\mathrm{Si}$, and no significant differences between the FCVA-DLC and ECR-CVD-DLC films were observed. 


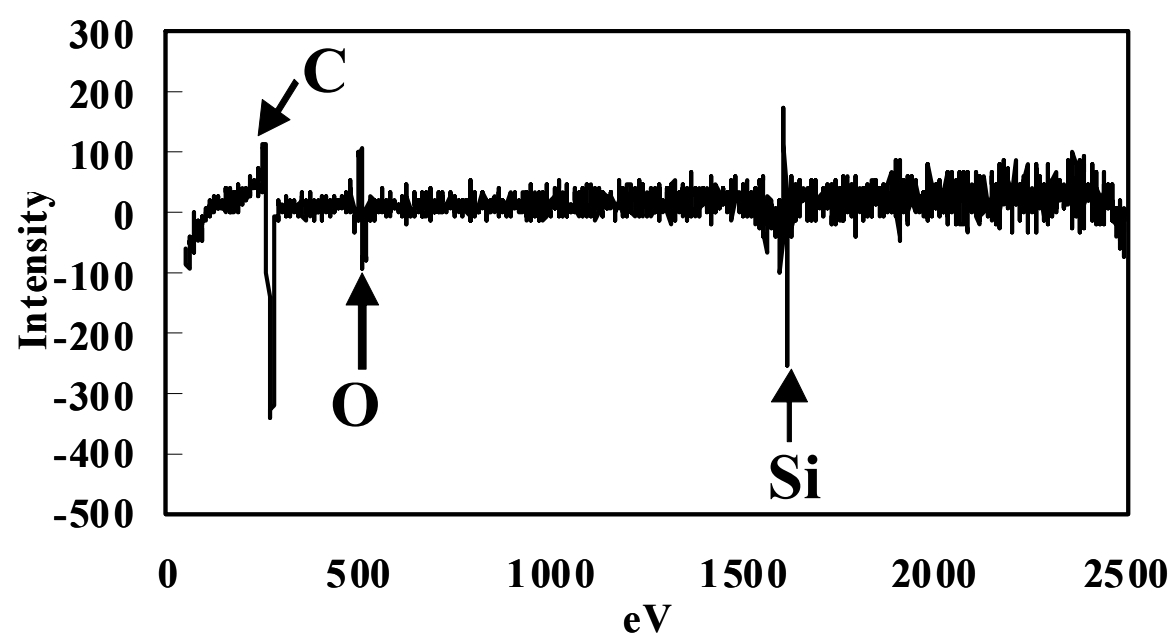

(a) FCVA-DLC $1 \mathrm{~nm}$

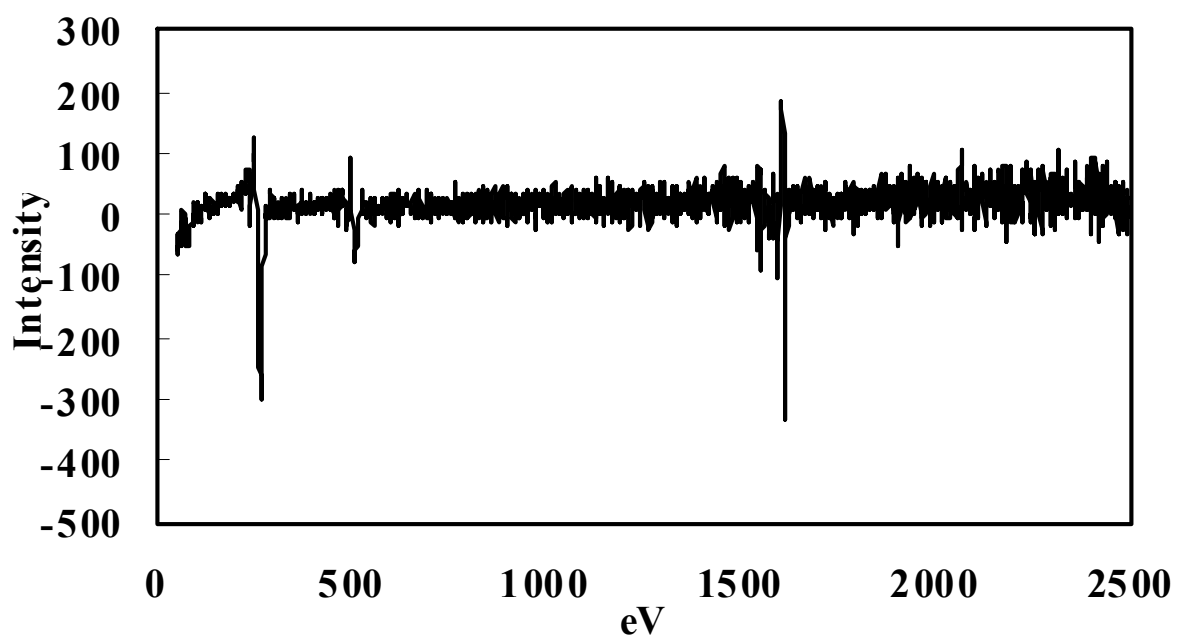

(b) ECR-CVD-DLC 1-nm

Fig. 15. AES spectra of top surfaces of 1-nm-thick FCVA and ECR-CVD DLC films.

The actual thicknesses of the 100-nm-thick DLC films were obtained by TEM and AES. The depth profiles were shown in Fig. 16.The FCVA-DLC and ECR-CVD-DLC films had actual thicknesses of 107 and $97 \mathrm{~nm}$ and their densities were 3.3 and $1.9 \mathrm{~g} / \mathrm{cm}^{3}$, evaluated by Rutherford back scattering (RBS), respectively (Miyake et al., 2009).

\subsubsection{Nanoindentation properties of DLC films}

The nanoindentation curves of FCVA-DLC and ECR-CVD-DLC films with a thickness of 100 $\mathrm{nm}$ are shown in Fig. 17. The indentation depth of the ECR-CVD-DLC film was greater than 


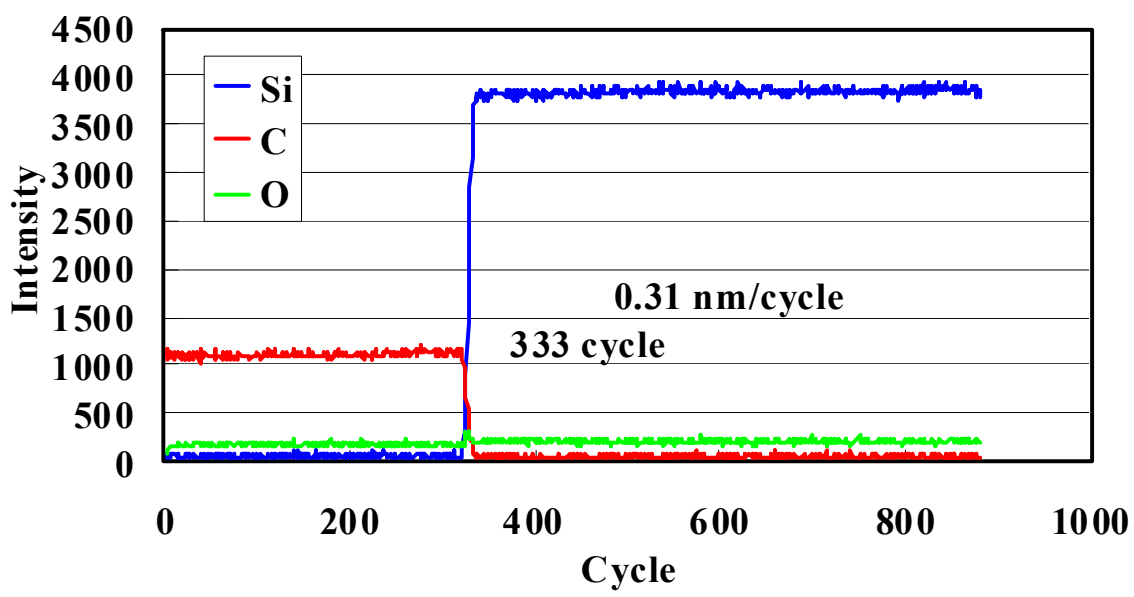

(a) FCVA-DLC 100-nm

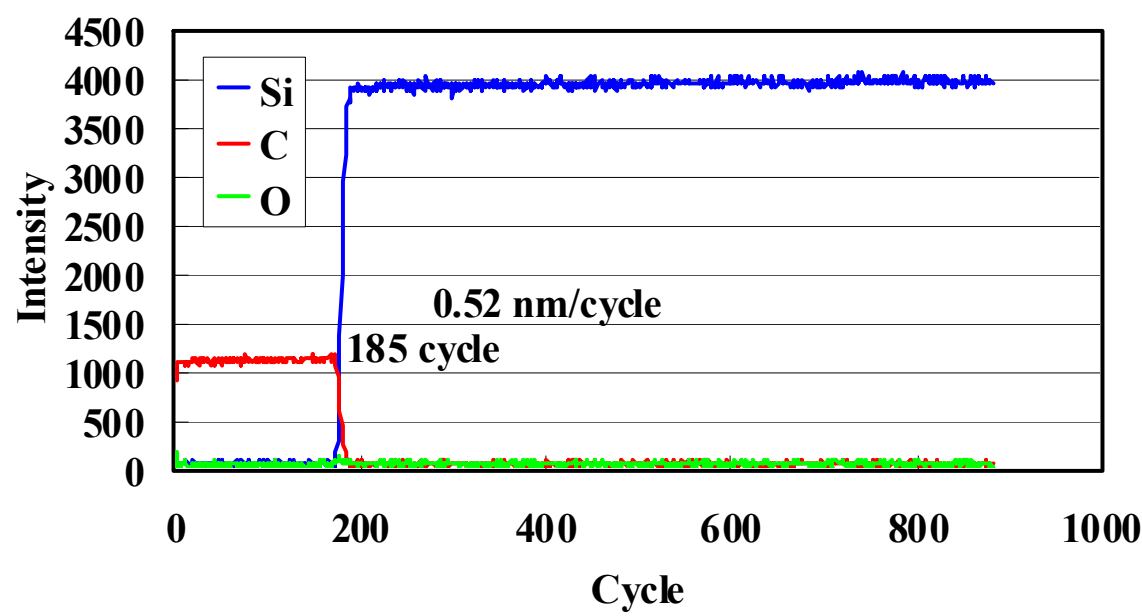

(b) ECR-CVD-DLC 100-nm

Fig. 16. AES depth profiles of 100-nm-thick DLC films.

that of the FCVA-DLC film. The FCVA-DLC film mainly exhibited elastic deformation. However, the ECR-CVD-DLC film exhibited greater energy dissipation at the same indentation load (Farhat et al., 1997; Miyake, 2003). The nanoindentation hardnesses of the

DLC films deposited by FCVA and ECR-CVD were 57 and $25 \mathrm{GPa}$, respectively, at a $40 \mu \mathrm{N}$ load. This high hardness of the FCVA-DLC film is similar to the reported hardness of 59 GPa for a 100-nm-thick FCVA-DLC film deposited under similar conditions (Shi et al., 1996). The density of our FCVA-DLC film was as high as $3.3 \mathrm{~g} / \mathrm{cm}^{3}$, nearly equal to the previously reported density of $3.37 \mathrm{~g} / \mathrm{cm}^{3}$ (Shi et al., 1996). Under our deposition conditions, the actual hardness of the films, regardless of the effect of the substrate, can be obtained. The FCVADLC film exhibited excellent resistance to nanometre-scale plastic deformation. 


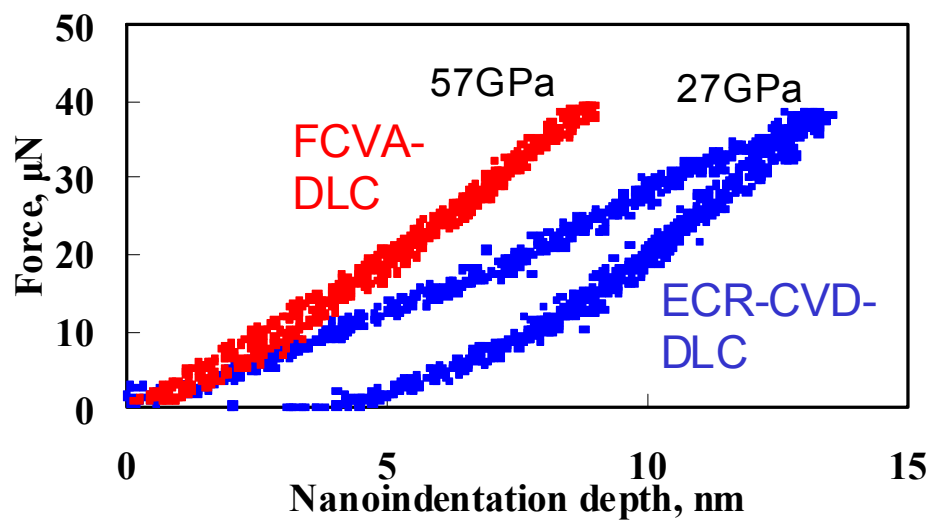

Fig. 17. Nanoindentation curves of 100-nm-thick DLC films.

The nanoindentation curves of the films with a target thickness of $5 \mathrm{~nm}$ are shown in Fig. 18 . In the nanoindentation loading curves of both DLC films, points of inflection (arrows in Fig. 18) can be observed when the indentation depth exceeds the film thickness. The points of inflection correspond to the onset of nanometer-scale plastic deformation of the thin films due to damage to the surface. Hardly any difference between the nanoindentation curves of the extremely thin DLC films deposited by FCVA and ECR-CVD was detected. It was difficult to evaluate the hardness of the DLC films with a thickness of a few nm by this nanoindentation test owing to the effect of the substrate (Lemoine et al., 2004).

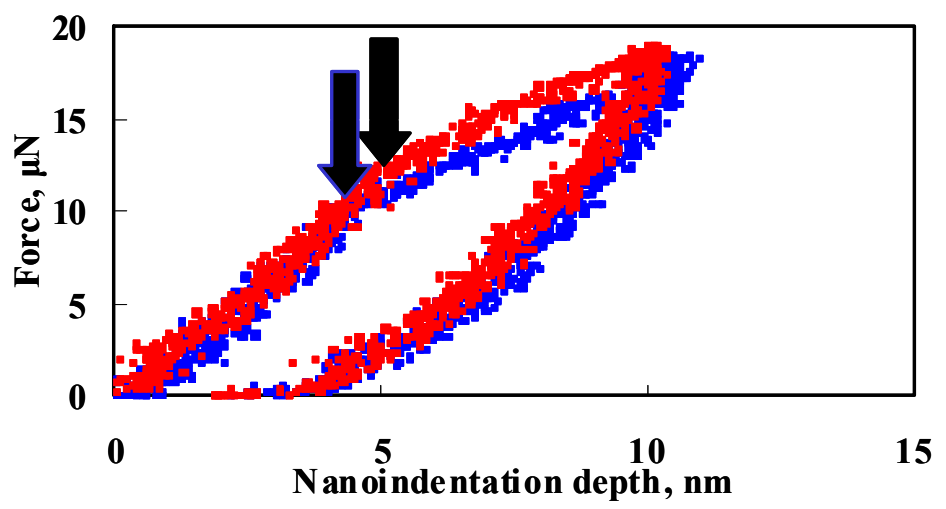

Fig. 18. Nanoindentation curves of various 5-nm-thick DLC films.

\subsubsection{Nanowear properties of DLC films}

Figure 19(a) shows the method used to evaluate nanowear and Fig. 19(b) shows crosssectional profiles of the $\mathrm{Si}(100)$ substrate. Wear of nearly $3 \mathrm{~nm}$ depth and protuberances with a height of $1 \mathrm{~nm}$ were observed. The nanowear and cross-sectional profiles of 2- and 1-nmthick DLC films are shown in Figs. 20 and 21, respectively. Wear of approximately 3-5 nm was observed in the ECR-CVD-DLC film. In contrast, no wear of the FCVA-DLC film can be observed in Figs. 20(a) and 21(a). 

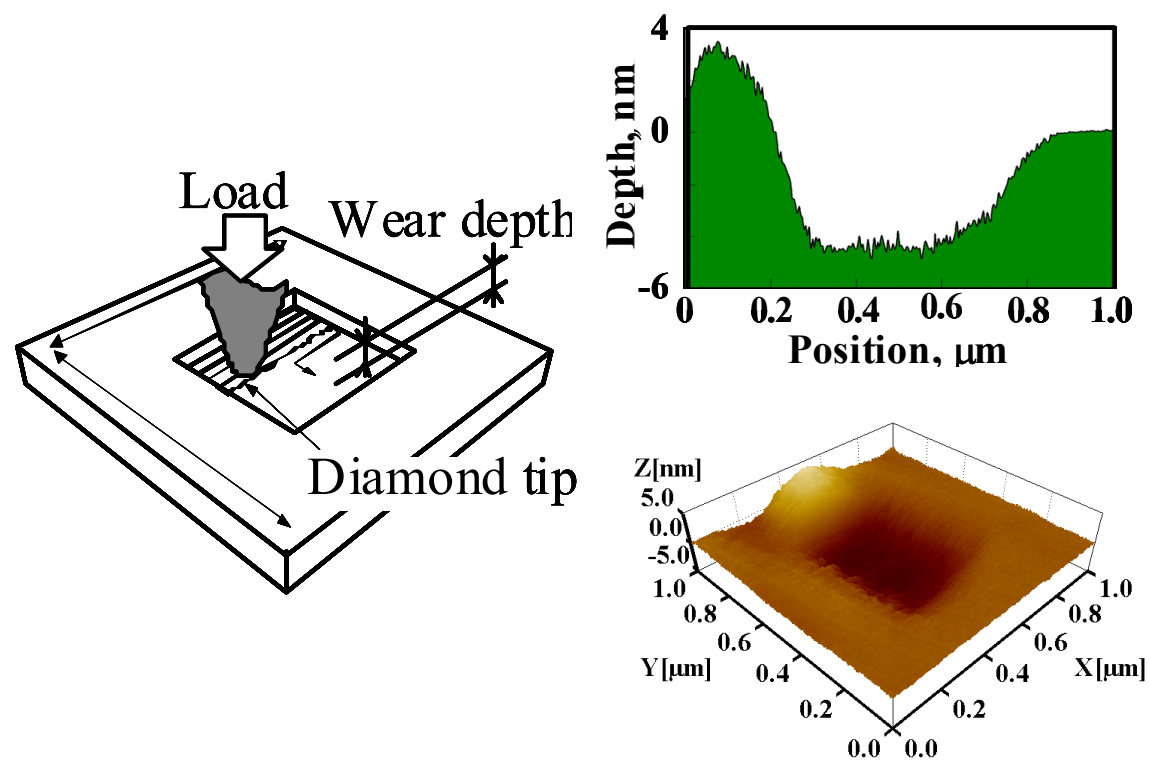

(a) A nanowear test

(b) Wear

Fig. 19. Nanowear test (a) and wear profiles of Si substrate (b).
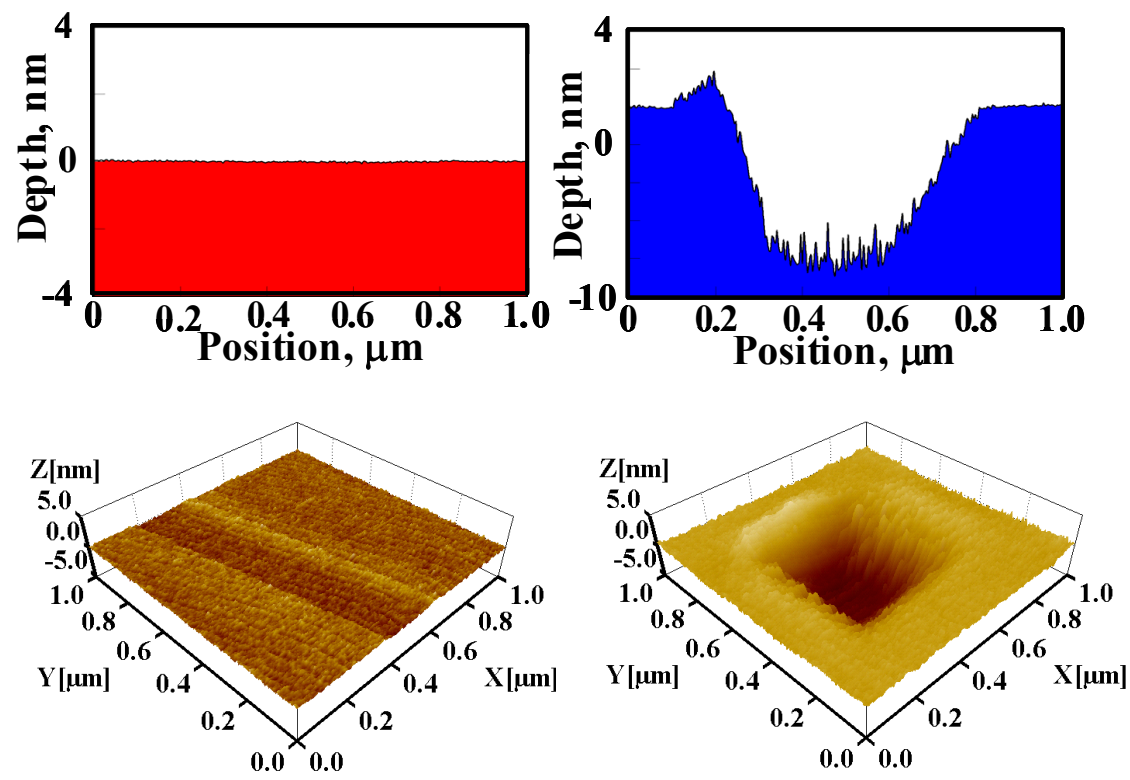

(a) FCVA-DLC

(b) ECR-CVD-DLC

Fig. 20. Wear profiles of 2-nm-thick DLC films. 

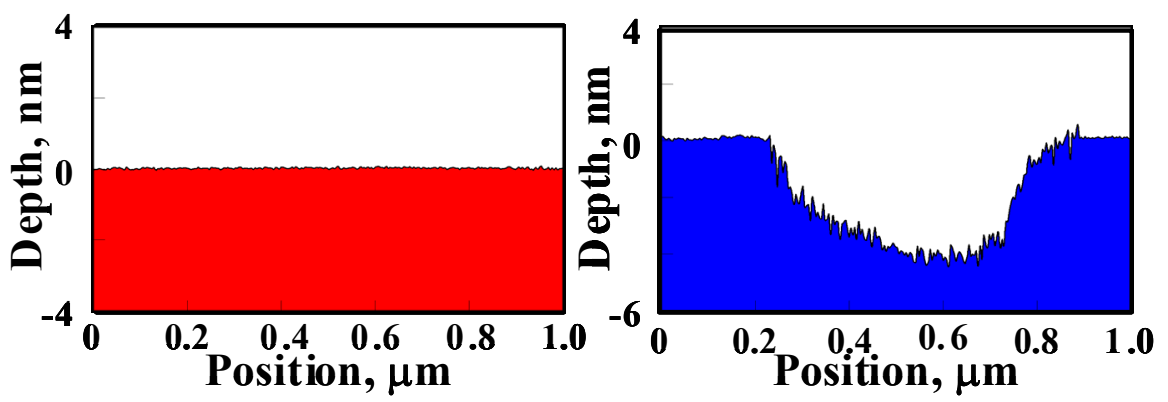

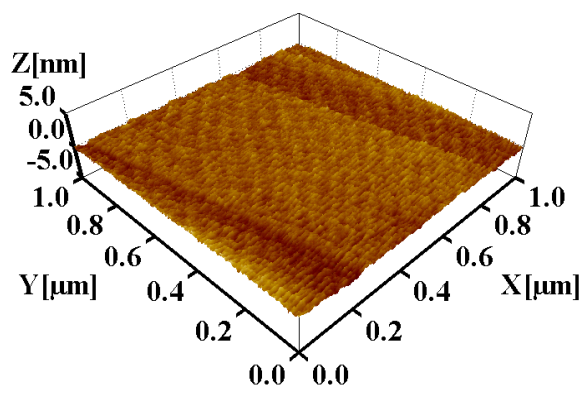

(a) FCVA-DLC

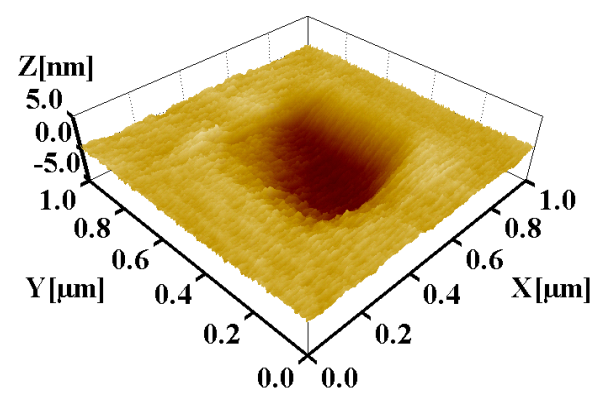

(b) ECR-CVD-DLC

Fig. 21. Wear profiles of 1-nm-thick DLC films.
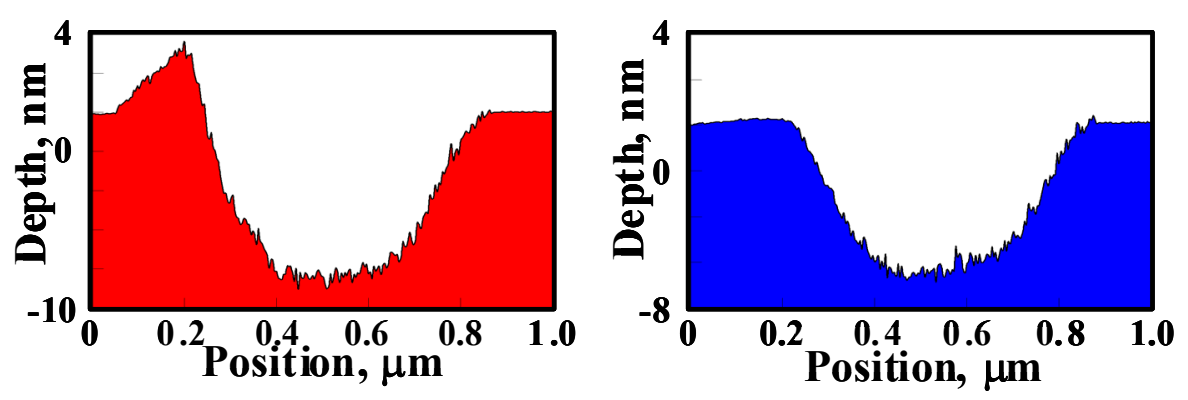

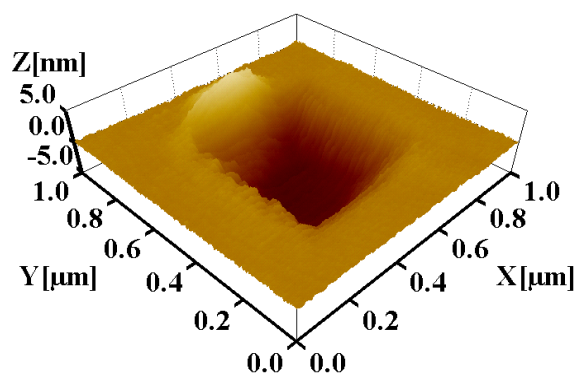

(a) FCVA-DLC

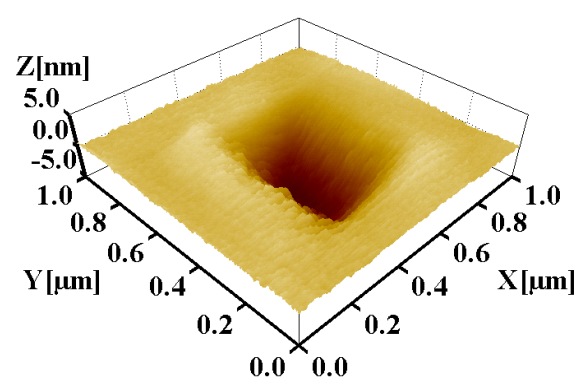

(b) ECR-CVD-DLC

Fig. 22. Wear profiles of 0.8-nm-thick DLC films 
These DLC films are extremely thin. Therefore, atomic-scale defects in the film affect the nanowear properties. The density of the FCVA-DLC film was higher than that of the ECRCVD-DLC film. The ECR-CVD-DLC film contained a hydrogen terminated carbon network. Therefore, plastic deformation was more easily caused by friction stress in the ECR-CVDDLC film than in the FCVA-DLC film. However, as shown in Fig. 22, the wear depth of the 0.8-nm-thick FCVA-DLC film increased rapidly with the number of sliding cycles and is similar to those of the ECR-CVD-DLC film and Si surface. The 0.8-nm-thick FCVA-DLC film did not exhibit superior nanowear resistance.

The nanowear depth dependence on the number of sliding cycles for various DLC films is shown in Fig. 23. The wear depths of 1- and 2-nm-thick FCVA-DLC films were extremely low, less than $1 \mathrm{~nm}$ even after 20 sliding cycles of diamond tip scanning, as shown in Fig. 23(a). In contrast, the wear depths of 0.8-, 1- and 2-nm-thick ECR-CVD-DLC films were nearly $1 \mathrm{~nm}$ after one sliding cycle and exceeded the their film thickness after a few sliding cycles, as shown in Fig. 23(b). These results reveal the variation of wear resistance among these extremely thin DLC films and the superior and excellent wear resistance of FCVADLC films compared with ECR-CVD films.
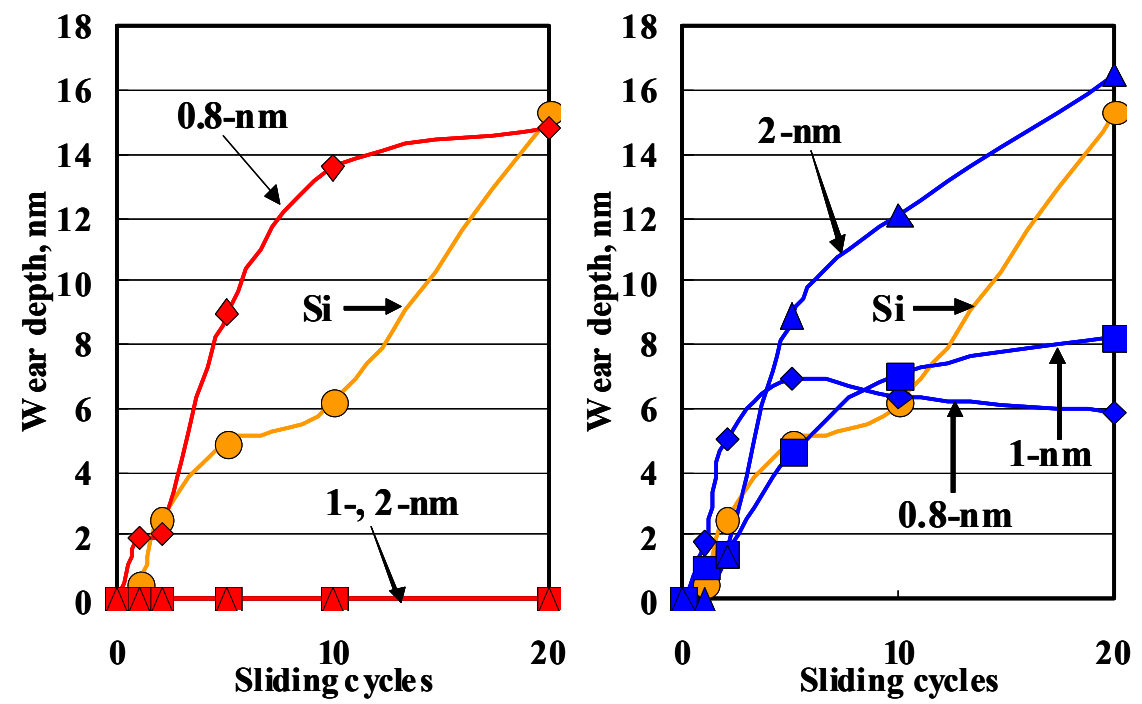

Fig. 23. Nanowear depth dependence on number of sliding cycles.

\subsection{Micro-tribological properties of heat treated PFPE lubricant}

\subsubsection{Heat treatment of PFPF lubricant}

Perpendicular hard disks with and without heat treatment were used as specimens in our study. PFPE lubricant was coated on these disks. Heat treatment was performed for $15 \mathrm{~min}$ at $100^{\circ}$. The lubricant thickness of the untreated hard disk was $1.1 \mathrm{~nm}$ and that of the disk with heat treatment was $0.95 \mathrm{~nm}$. The roughness of the disks both with and without heat treatment was found to be $0.4 \mathrm{~nm} \mathrm{Ra}$. 


\subsubsection{Resonance of transducer system}

To investigate the viscoelastic properties of the hard disks, it is necessary to know the resonance of the tip indenter system. Figure 24 shows the amplitude and phase lag of the indenter tip when the tip is free of contact. The diamond indenter tip was vibrated at 1-300 $\mathrm{Hz}$. The resonance frequency was found to be approximately 130-140 Hz. Physical parameters such as the spring constant, mass and damping coefficient of the transducer system were evaluated based on the relationship between amplitude and vertical motion of the indenter tip, as shown in Fig. 24. The spring constant was found to be $209 \mathrm{~N} / \mathrm{m}$, the mass of the system was $262 \mathrm{mg}$ and the damping coefficient was $0.049 \mathrm{~kg} / \mathrm{s}$.

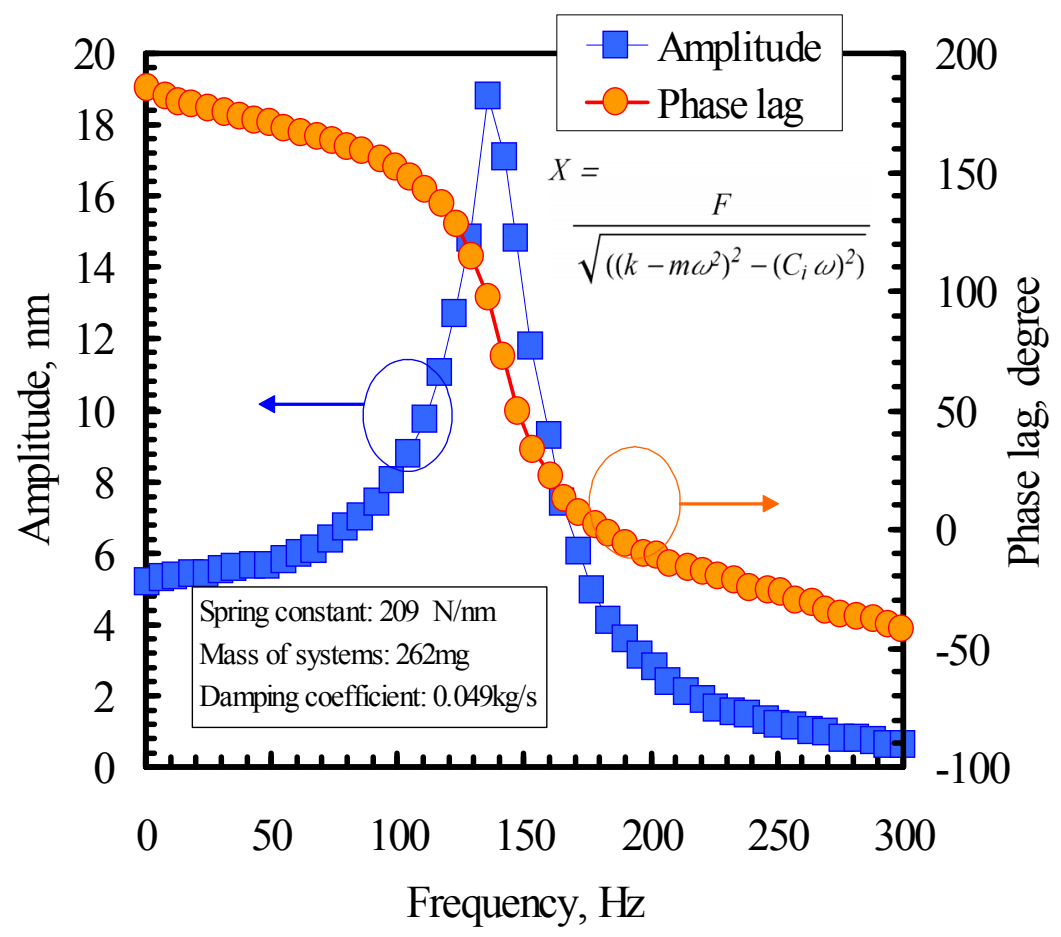

Fig. 24. Relationship between amplitude and vertical motion of indenter tip.

\subsubsection{Nanoindentation hardness of PFPE coated disks}

Figure 25 shows quasi-static nanoindentation curves obtained from the hardness test with a $20 \mathrm{~N}$ load. As shown in Fig. 25(a), the maximum indentation depth in the hill of the untreated disk was approximately $6.0 \mathrm{~nm}$ and that of the heat-treated disk was $4.0 \mathrm{~nm}$. The maximum indentation depth of the hill was greater than that of the valley, as observed in Figs. 25(a) and 25(b). As shown in Fig. 25(c), for both disks, the hardness in the valley was higher than that on the hill. As a result, the nanoindentation hardness of the hill of the heattreated hard disk was $8.0 \mathrm{GPa}$ and that of the valley was $14.0 \mathrm{GPa}$. It is clear that the hardness of the hard disk was increased by heat treatment. 


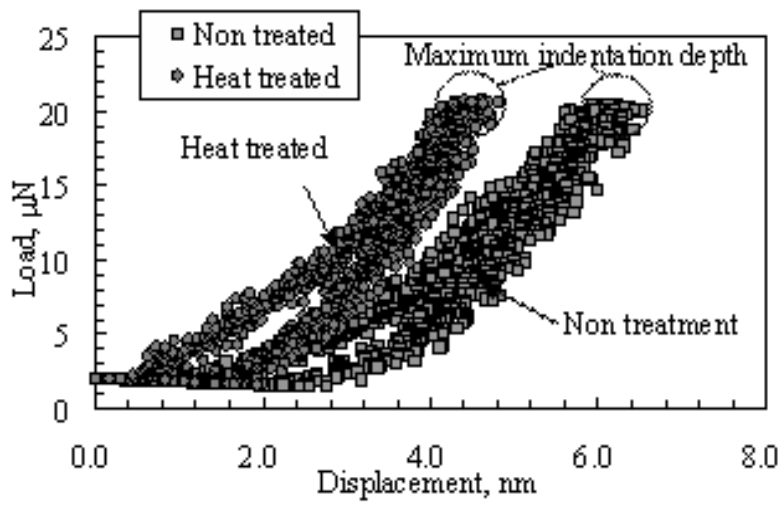

(a) Nano-indentation curve of hill part

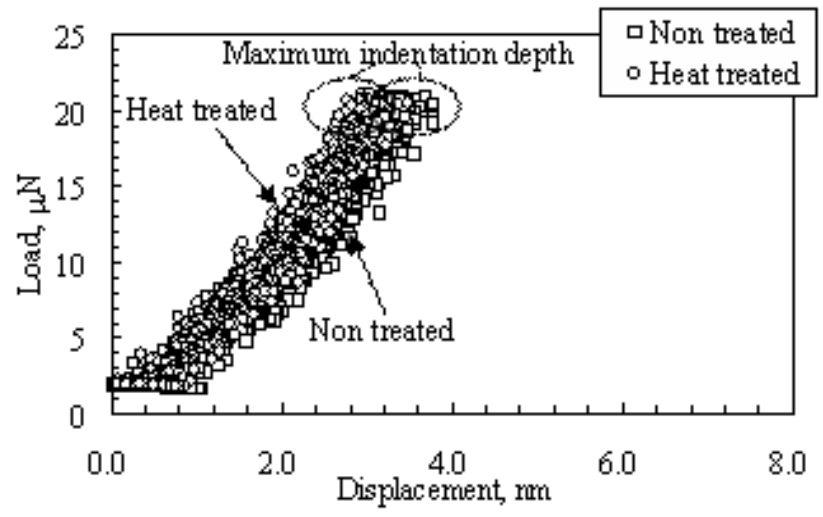

(b) Nano-indentation curve of valley part

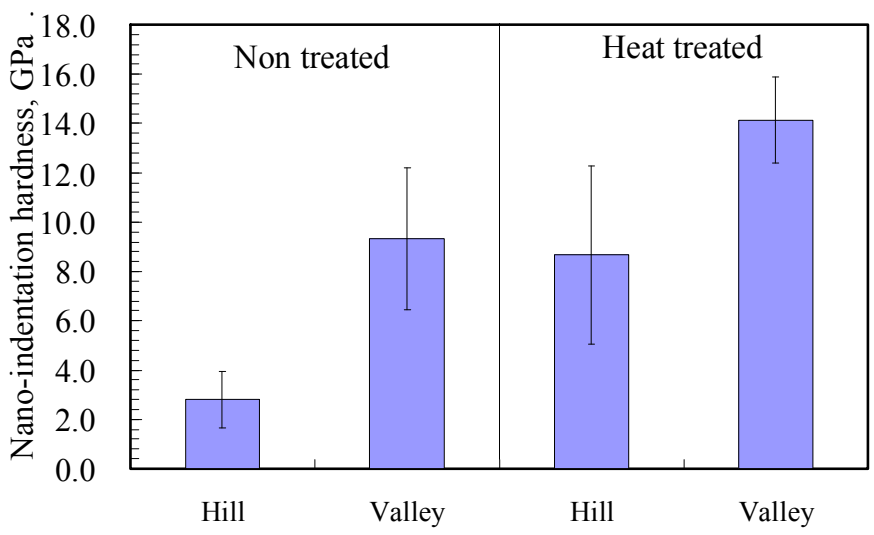

(c) Average of nanoindentation hardness

Fig. 25. Variation in nanoindentation hardness for untreated and heat-treated disks. 


\subsubsection{Viscoelastic properties of PFPE lubricant}

Figure 26 shows the viscoelastic properties of untreated and heat-treated disks. The storage modulus of the hill of the untreated disk surface was larger than that of the valley at all loads. The storage moduli of the valleys were more variable than those of the hills as shown in Fig. 26(a). On the other hand, for the heat-treated disk, the storage modulus of the valley part was larger than that of the hill part. The storage modulus of both the hill and valley increased after heat treatment. These results are consistent with the results for the nanoindentation hardness. The loss modulus of the valley part of the untreated disk surface was larger than that of the hill part, as shown in Fig. 26(b). Moreover, the loss modulus of the heat-treated disk exhibited the same tendency as that of the untreated disk surface. As shown in Fig. 26(c), $\tan \delta$ for the valley part of the untreated disk surface was larger than that for the hill part. Tan $\delta$ for the hill part and valley part of the heat-treated disk surface has the same behavior as that for the untreated disk surface. These results are related to the quantity of lubricant in the valley part.

\subsubsection{Viscoelastic properties of PFPE lubricant after microwear test}

To determine the motion of PFPE by sliding testing, the viscoelastic properties were evaluated in the hill and valley parts by a microwear test. Surface and cross-sectional profiles of the heat-treated and untreated disks under a load of $30 \mu \mathrm{N}$ are shown in Fig. 27. The wear depth of the untreated disk surface was about $3.5 \mathrm{~nm}$, while that of the heattreated disk was about $3.0 \mathrm{~nm}$. The microwear properties depended on the load. The same tendency was observed for the wear volume. Figure 28 shows the results of the microwear test of untreated and heat-treated disk surfaces. The wear depth of the heat-treated disk was decreased by heat treatment for all applied loads. This finding is consistent with the results of the quasi-static nanoindentation tests.

Figure 29 shows the storage moduli of the wear and nonwear parts. As shown in Fig. 29(a), in the hill part of the untreated disk surface, the storage modulus of the wear part was different from that of the nonwear part. However, in the hill part of the heat-treated disk, the storage modulus of the wear part was markedly different from that of the nonwear part. As shown in Fig. 29(b), the changes in the storage modulus of the wear part of the untreated surface disk were greater in the valley part than in the hill part. In the case of the heattreated disk, the storage modulus of the wear part exhibited much greater fluctuations in both the valley part and the hill part than those of the nonwear part.

The loss moduli of the wear and nonwear parts for the heat-treated and untreated disks are displayed in Fig. 30. As shown in Fig. 30(a), for the untreated disk and the heat-treated disk surfaces, the loss moduli of the wear part in the hill are similar to those of the nonwear parts. Similarly, for both the heat-treated and untreated disk surfaces, the loss moduli of the wear part in the valley were different from those of the nonwear part.

Figure 31 shows $\tan \delta$ for the wear part of the heat-treated and untreated disk surfaces. In the hill part of the untreated disk surface, at loads of $10-90 \mu \mathrm{N}$, $\tan \delta$ for the wear part and nonwear part were the same. However, for the heat-treated disk, at higher loads of 70-90 $\mu \mathrm{N}, \tan \delta$ for the wear part was smaller than that for the nonwear part, and $\tan \delta$ in the valley part exhibited the same tendency in the hill part. It is considered that PFPE lubricant was present on the wear part. On the other hand, it is thought that $\tan \delta$ for the heat-treated disk surface was lower than that for the untreated disk surface because the PFPE lubricant was solidified and removed during the sliding test. 


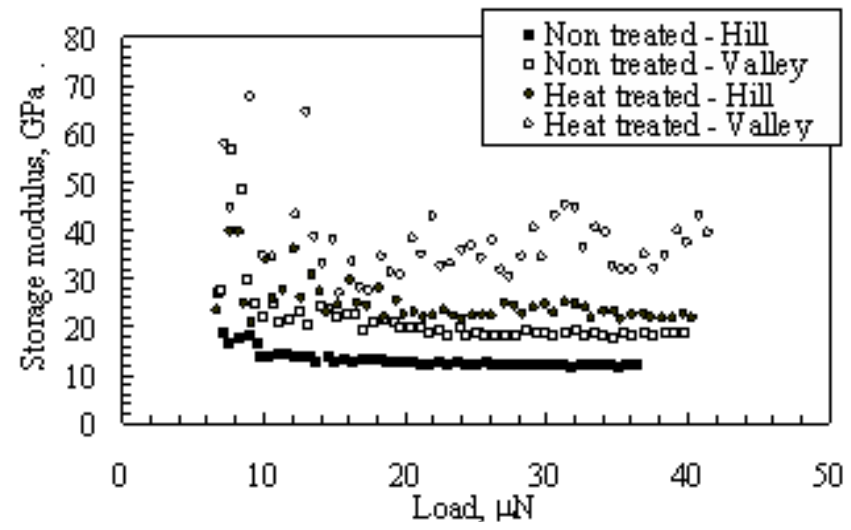

(a) Storage modulus

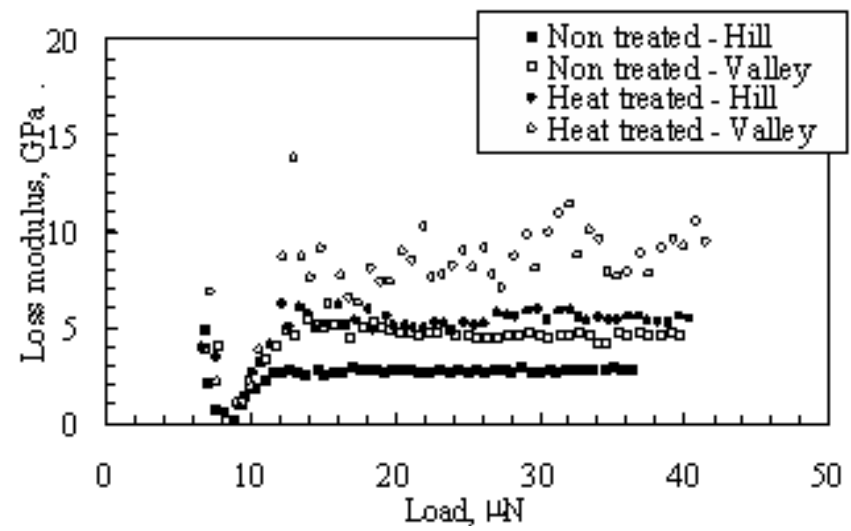

(b) Loss modulus

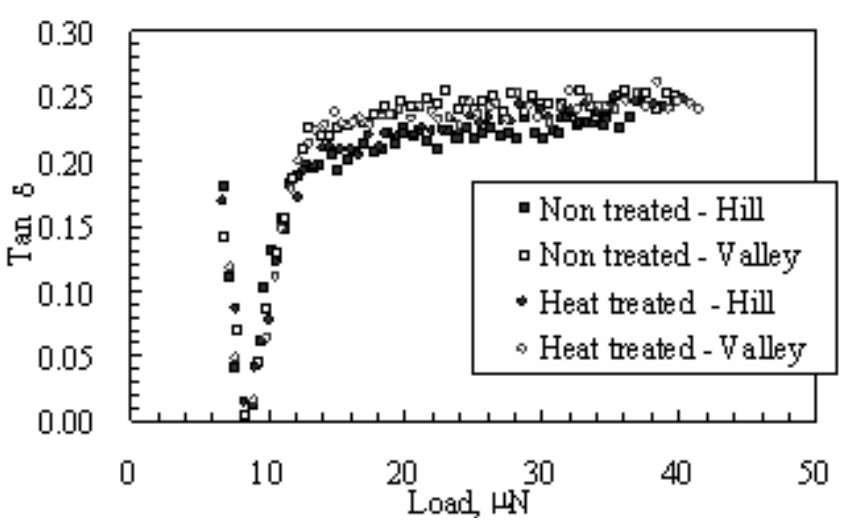

(c) $\operatorname{Tan} \delta$

Fig. 26. Viscoelastic properties of untreated and heat-treated disks. 

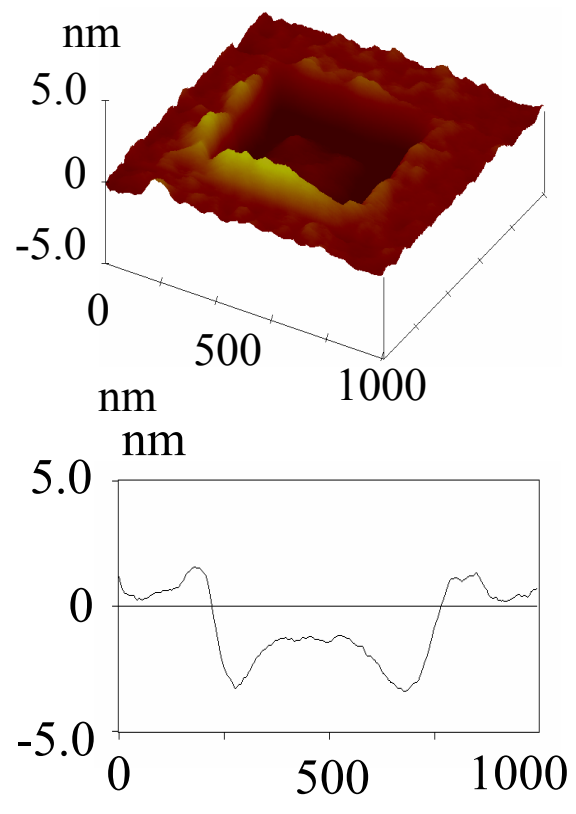

(a) Non treated
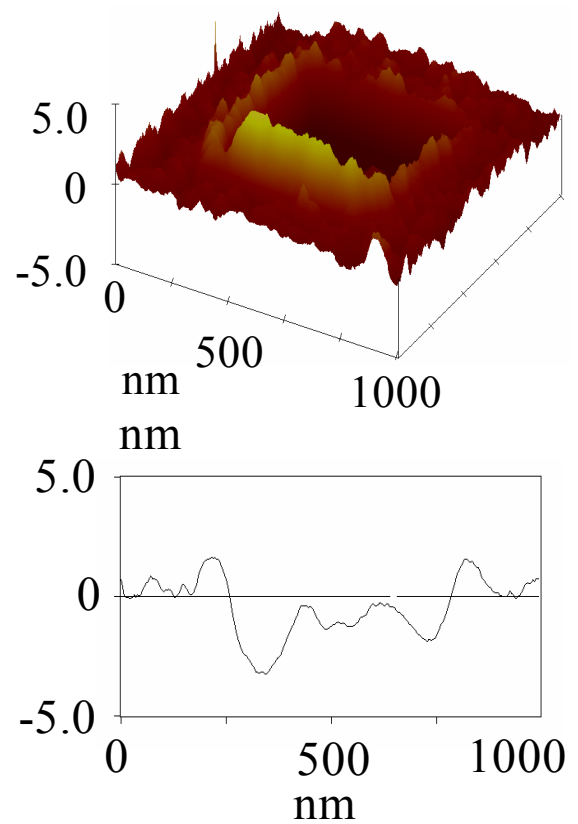

(b) Heat treated

Fig. 27. Surface and cross-sectional profiles of untreated and heat treated disk surfaces. 


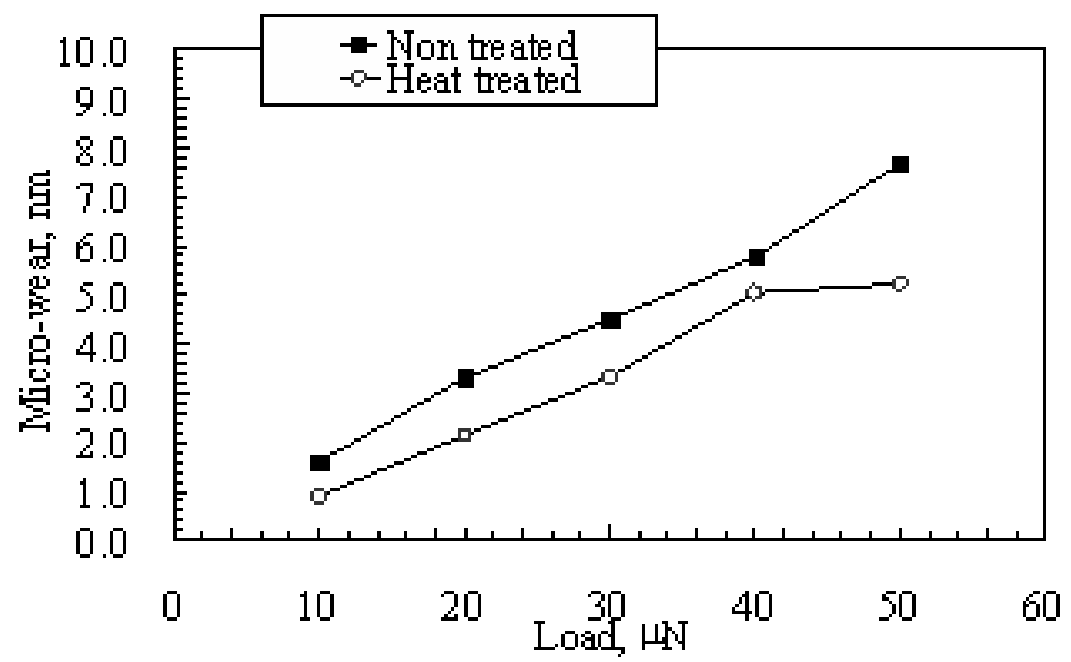

(a) Wear depth

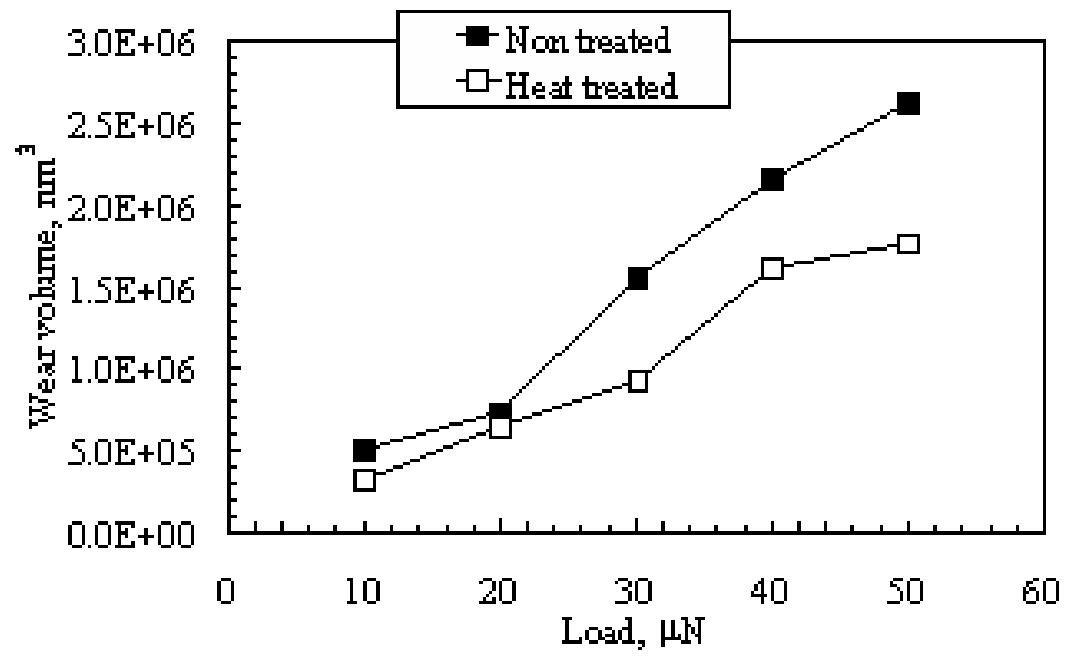

(b) Wear volume

Fig. 28. Dependence of microwear properties on applied load. 

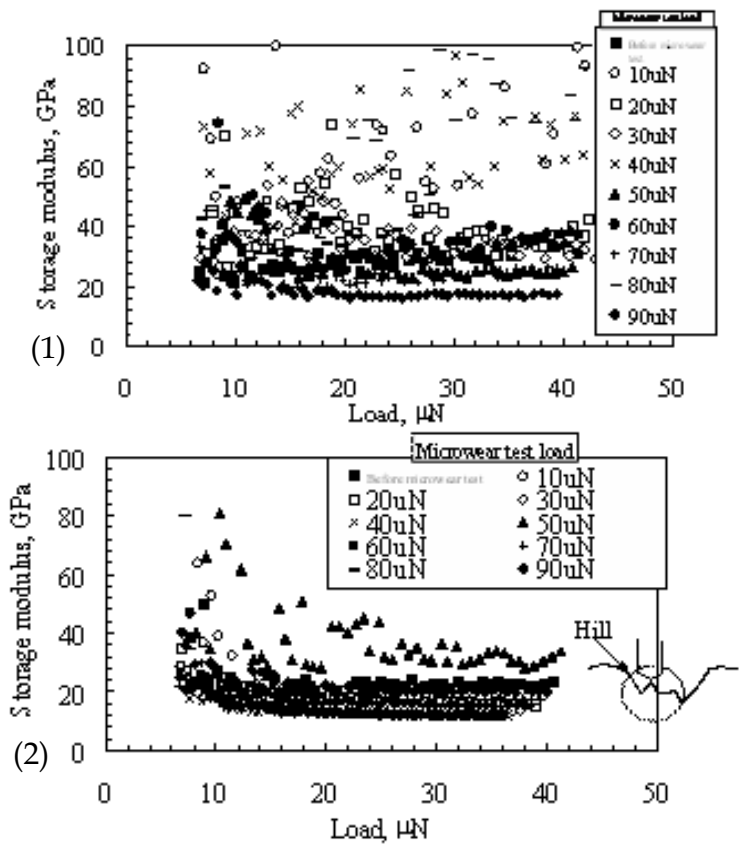

(a) Hill, (1) Untreated, (2) Heat-treated
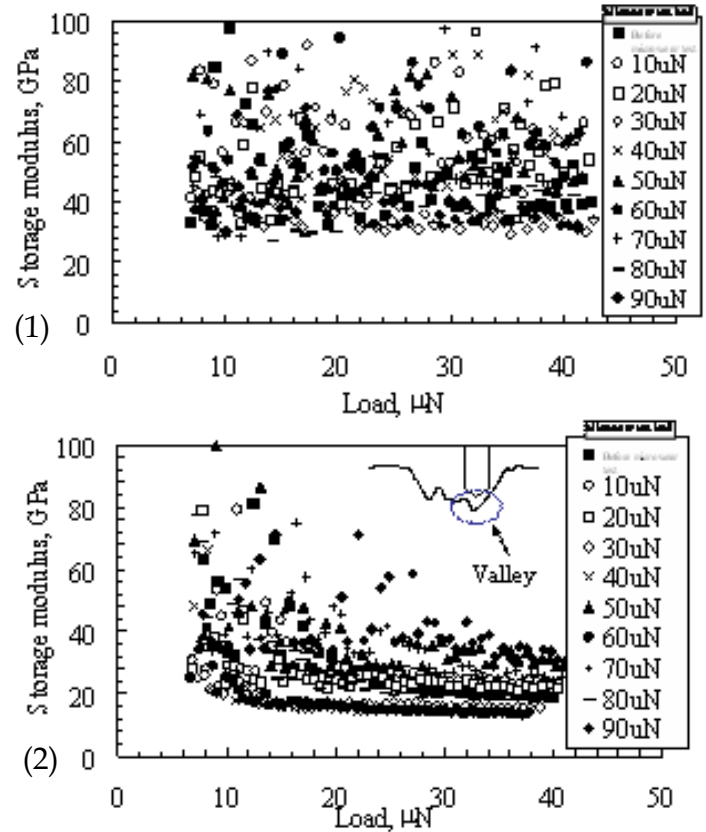

(b) Valley, (1) Untreated, (2) Heat-treated

Fig. 29. Storage moduli of wear and nonwear parts. 

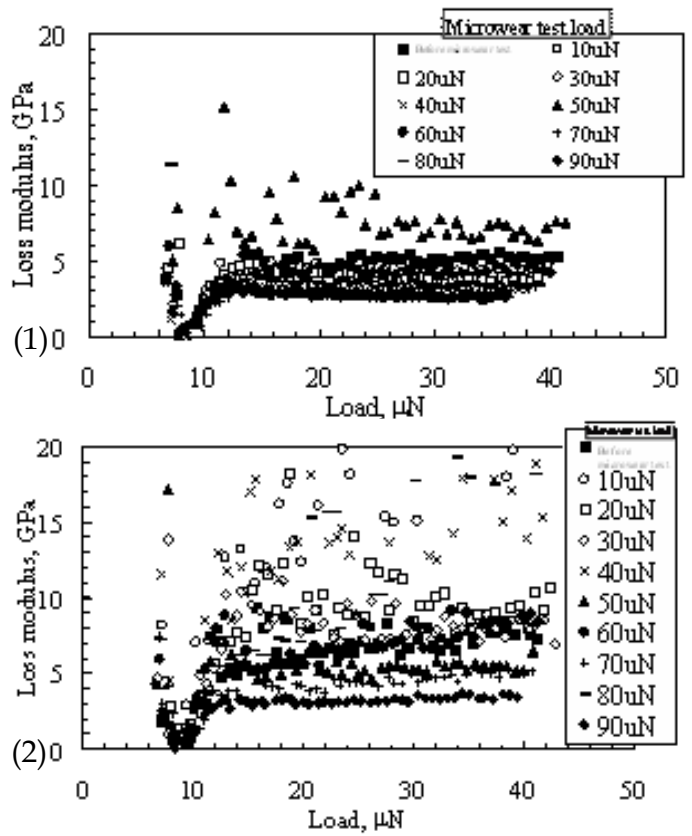

(a) Hill, (1) Untreated, (2) Heat-treated
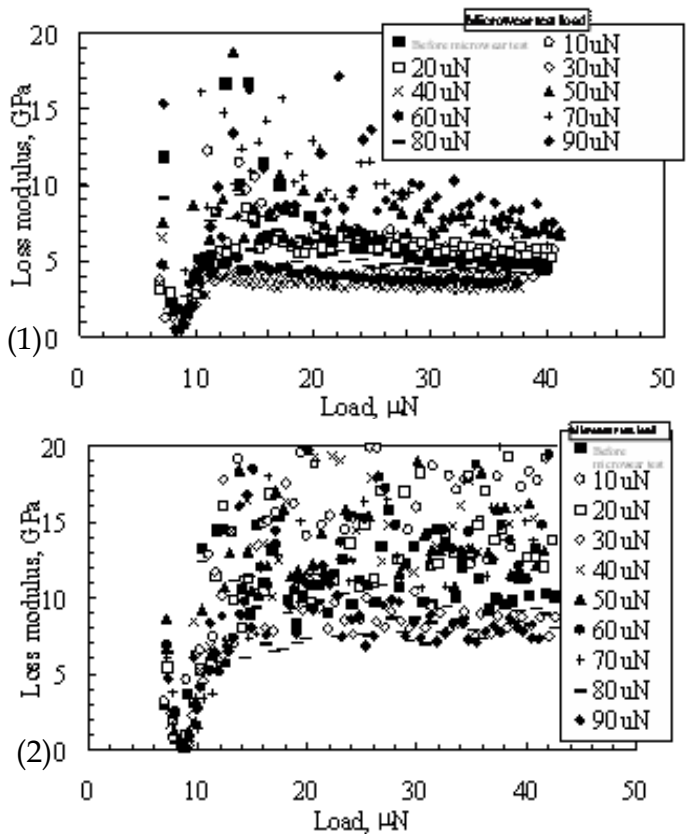

(b) Valley, (1) Untreated, (2) Heat-treated

Fig. 30. Loss moduli of wear and nonwear parts. 

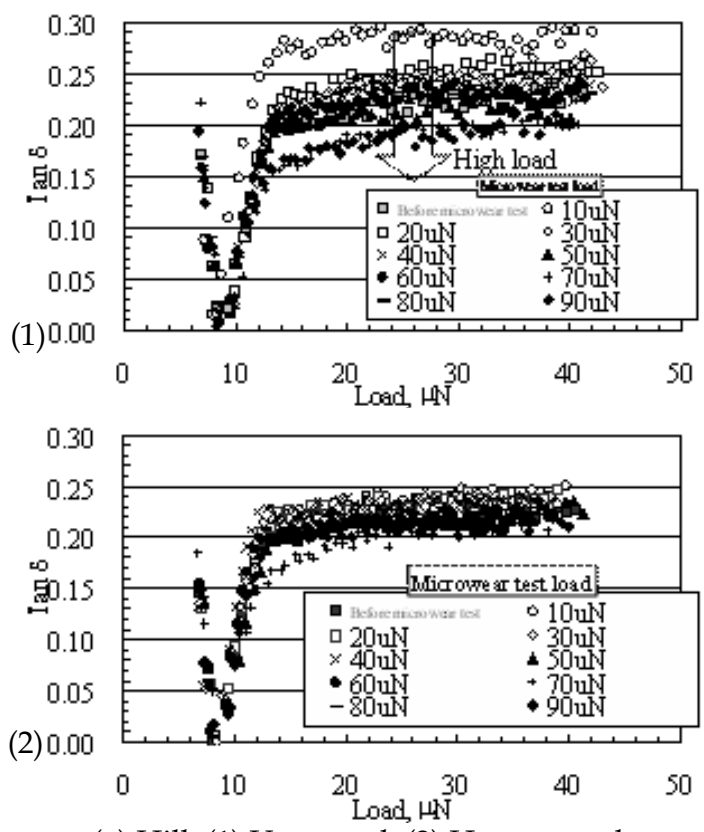

(a) Hill, (1) Untreated, (2) Heat-treated
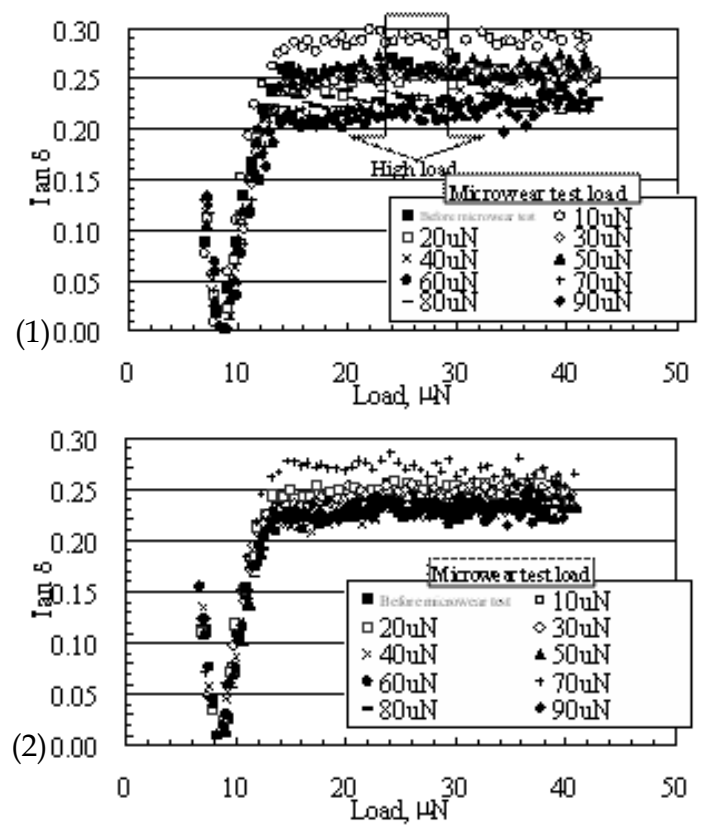

(b) Valley, (1) Untreated, (2) Heat-treated

Fig. 31. Tan $\delta$ for untreated and heat-treated disk surfaces after microwear test. 


\section{Conclusion}

In this chapter we reported the present status of research on the nanomechanical evaluation of ultrathin films using AFM for hard disk applications. As stated, nanomechanical evaluation involves the evaluation of nanoindentation hardness, surface deformation properties, nanoscale wear properties and nanotribological properties.

Extremely thin nitrogen-containing carbon (C-N) films with thicknesses of 3, 6 and $9 \mathrm{~nm}$ were prepared as a protective overcoat on CoCrTa magnetic disks and their microtribological and micromechanical properties were evaluated by AFM. It is clear that both the nanoindentation hardness and microwear resistance of complex C-N films were significantly improved by complex treatment and He addition. The 3-nm-thick complex C-N films exhibited excellent wear resistance compared with other films, resulting from their graded composition. The effect of the deterioration of the layer generated by plasma irradiation on the magnetic spacing was negligible since a plasma-irradiated layer had a thickness of less than $1 \mathrm{~nm}$. In contrast, the effect of the complex treatment on the mechanical properties of C-N films was significant.

According to the results of AFM, the nanoindentation hardnesses of the 100-nm-thick DLC films deposited by FCVA and ECR-CVD were 57 and $25 \mathrm{GPa}$, respectively, at a $40 \mu \mathrm{N}$ load. Hardly any difference between the nanoindentation curves of extremely thin DLC films deposited by FCVA-CVD and ECR-CVD was detected, although it was difficult to evaluate the hardness of the DLC films with a thickness of a few $\mathrm{nm}$ by this nanoindentation test. In contrast, nm wear tests were successfully used to evaluate the surface of the extremely thin DLC films after wear and to clarify their mechanical properties. The wear depths of 1- and 2nm-thick FCVA-DLC films were extremely low, less than $1 \mathrm{~nm}$ even after 20 sliding cycles. However, the wear depth of the 0.8-nm-thick FCVA-DLC film increased rapidly with the number of sliding cycles similarly to the result for a Si substrate. The wear depths of the 0.8-, 1.0- and 2.0-nm-thick ECR-CVD-DLC films were nearly $1 \mathrm{~nm}$ after one sliding cycle and exceeded the film thickness after a few sliding cycles. These results reveal the variation of wear resistance among these extremely thin DLC films and the superior wear resistance of FCVA-DLC thin films.

The microtribological properties of heat-treated disks were investigated using the force modulation method with SPM. In the quasi-static nanoindentation hardness test, the hardness of the hard disk was found to increase after heat treatment. The evaluation of the viscoelastic properties showed that $\tan \delta$ for the valley part was higher than that for the hill part. The microwear depth and volume of the disks were decreased by heat treatment. This is consistent with the result of the quasi-static nanoindentation hardness test of the heat-treated disk. Lubricant present on the heat-treated disk was removed by sliding under high loads. AFM plays a vital role in the nanomechanical evaluation of ultrathin films used for hard magnetic disks. It is possible to evaluate the micromechanical and microtribological properties of such ultrathin films and to apply these evaluation methods in future works.

\section{Acknowledgment}

The research work was partly supported by the Storage Research Consortium (SRC). 


\section{References}

Asif, S.A.S.; Wahl, K.J. \& Colton, R.J. (1999). Nanoindentation and contact stiffness measurement using force modulation with a capacitive load-displacement transducer, Rev Sci Inst., Vol. 70, pp. 2408-2413. ISSN 0034-6748

Bhushan, B. (1995). Handbook of Micro/Nanotribology, CRC Press, Inc. 1997, pp.321-322. ISBN 0-8493-8401-X, USA

Cutinogco, E.C.; Li, D.; Chung, Y.; \& Bhatia, S.C. (1996). Tribological behavior of amorphous carbon nitride overcoats for magnetic thin-film rigid disks, ASME Trans. J. Tribology, Vol 118, 7, pp. 543-548. ISSN 0022-2305

Doerner, M.F.; Gardner, D.S. \& Nix, W.D. (1986). Plastic properties of thin films on substrates as measured by submicron indentation hardness and substrate curvature techniques, J. Mater. Res., Vol. 1, 6, pp. 845-851. ISSN 0884-2914

Farhat, Z.N.; Ding, Y.; Northwood, D.O. \& Alps, A.T. (1997). Nanoindentation and friction studies on Ti-based nanolaminated films, Surf. Coat. Technol., Vol. 89, pp. 24-30. ISSN 0257-8972

Ferrari, A.C. (2002). Determination of bonding in diamond-like carbon by raman spectroscopy, Diamond and Related Materials, Vol. 11, pp. 1053-1061. ISSN 0925-9635

Hyodo, H.; Yamamoto, T. \& Toyoguchi, T. (2001). Properties of tetrahedral amorphous carbon film by filtered cathodic arc deposition for disk overcoat, IEEE Trans. on Magn., Vol. 37, pp. 1789.-1791. ISSN 0018-9464

Kaneko, R.; Oguchi, S.; Miyamoto, T.; Andoh, Y. \& Miyake, S. (1990). Micro-tribology for magnetic recording, STLE Publication, SP-27, 1990, pp. 31-34

Lemoine, P.; Quinn, J.P.; Maguire, P. \& McLaughlin, J.A. (2004). Comparing hardness and wear data for tetrahedral amorphous carbon films, Wear, Vol. 257, pp. 509-522. ISSN 0043-1648

Lemoinea, P.; Quinna, J.P.; Maguirea, P.D.; Zhaob,J.F. \& McLaughlina, J.A. (2007). Intrinsic mechanical properties of ultra-thin amorphous carbon layers, Applied Surface Science, Vol. 253, 14, pp. 6165-6175. ISSN 0169-4332

Liu, A.Y. \& Cohen, M.L. (1989). Prediction of new low compressibility solid, Science, Vol. 245, pp. 841-842. ISSN 0036-8075

Liu, A.Y. \& Cohe, M.L. (1990). Structure properties and electronic structure of lowcompressibility materials: $\beta-\mathrm{Si}_{3} \mathrm{~N}_{4}$ and hypothetical $\beta-\mathrm{C}_{3} \mathrm{~N}_{4}$. Physical Review, Vol. B41, pp. 10727-10734. ISSN 1050-2947

Miyake, S.; Kaneko, R.; Kikuya, Y.; \& Sugimoto. I. (1991). Micro-tribological studies on fluorinated carbon film, Trans. ASME J. Tribology, Vol. 113, pp. 384-389. ISSN 07424787

Miyake, S.; Kaneko, R. \& Miyamoto, T. (1992). Micro- and macro-tribological improvement of CVD carbon film by the inclusion of silicon, Diamond Films Technol., Vol. 1, 4, pp. 205-217. ISSN 0917-4540

Miyake, S.; Miyamoto, T. \& Kaneko, R. (1993). Microtribological improvement of carbon film by silicon inclusion and fluorination, Wear, Vol. 168, pp. 155-159. ISSN 0043-1648

Miyake, S. (1994). Microtribology of Carbonaceous films, approach to atomic scale zero wear, Trans. of the Mater. Res. Soci. of Japan, , 1994, 15B, pp. 919-922. ISSN 1382-3469 
Miyake, S.; Watanabe, S.; Miyazawa, H.; Murakawa, M.; Kaneko, R. \& Miyamoto, T. (1994). Micro scratch hardness increasing of ion plated carbon film by nitrogen inclusion evaluated by atomic force microscopy, Appl. Phys. Lett., Vol. 65, 9, pp. 3206-3208. ISSN 0003-6951

Miyake, S.; Watanabe, S.; Miyazawa, H.; Murakawa, M.; Kaneko, R. \& Miyamoto, T. (1997). Modification of nanometer scale wear of nitrogen-containing carbon film due to ion implantation, Nuclear Inst. and Methods in Phys. Res., Vol. B 122, pp. 643-649. ISSN 0168-9002

Miyake, S.; Sekine, Y. \& Watanabe, S. (2002). Surface modification of magnetic recording layer by low energy beam irradiation (in Japanese), J. Surf. Finishing Soc. Jpn., Vol. 53, pp. 939-944. ISSN 0915-1869

Miyake, S. (2003). Improvement of mechanical properties of nanometer period multilayer films at interfaces of each layer, J. Vac. Sci. Tech.,Vol. B21, 2, pp. 785-789. ISSN 07342101

Miyake, S. \& Wang, M. (2004). Mechanical properties of extremely thin B-C-N protective layer deposited with helium addition, Jpn. J. Appl Phys., Vol. 43, 6A, pp. 3566-3571. ISSN 0021-4922

Miyake, S.; Wang, M.; Saitoh, T.; \& Watanabe, S. (2005). Microtribological properties of B-C$\mathrm{N}$ extremely thin protective films deposited on plasma pretreated magnetic layers, Surf. Coat. Technol., Vol. 195, 2-3, pp. 214-226. ISSN 0257-8972

Miyake, S.; Saito, T.; Wang, M. \& Watanabe, S. (2006). Tribological properties of extremely thin protective carbon nitride films deposited on magnetic disk by complex treatment, Proc. IMechE Vol. 220 Part J: J. Engineering Tribology, JET124, IMechE, pp. 587-595. ISSN 1350-6501

Miyake, S.; Kurosaka, W. \& Oshimoto, K. (2009). Nanometer scale mechanical properties of extremely thin diamond-like carbon films, Tribology, Vol 3, No. 4, pp. 158-164. ISSN $0742-4787$

Robertson, J. (2008). Ultrathin carbon coating for magnetic storage technology, Int. J. Product Development, Vol. 5, 3-4, pp. 321-338. ISSN 1477-9056

Saitoh, T. \& Miyake, S. (2003). Dynamic deformation properties of the PFPE coated hard disk evaluated by force modulation method, (in Japanese). J Surf Finishing Soc Japan, Vol. 54, pp. 471-476. ISSN 0915-1869

Saperstein, D.D. \& Lin, J.L. (1990). Improved surface adhesion and coverage of perfluoropolyether lubrication following far-UV irradiation, Langmuir, Vol. 6, pp. 1522-1524. ISSN 0743-7463

Shi, X.; Tay, B.K.; Tan, H.S.; Zhong, L.;Tu, Y.Q.; Silva, S.R.P. \& Milne, W.I. (1996). Properties of carbon ion deposited tetrahedral amorphous carbon films as a function of ion energy, J. Appl. Phys. Vol. 79, 9, pp. 7234-7240. ISSN 0021-8979

Sugimoto, I. \& Miyake, S. (1989). Optical emission studies on interaction between halogenated carbon species and noble gas during fuoropolymer sputtering, J. Appl. Phys., Vol. 65, 12, pp. 4639-4645. ISSN 0021-4922

Tani, H. (1999). Observation of PFPE lubricant film on magnetic disk surface by atomic force microscopy. IEEE Trans Magn., Vol. 35, pp. 2397-2399. ISSN 0018-9464 
White, R.L.; Bahatia, S.S.; Meek, S.W.; Friedenberg, M.C. \& Mate, C.M. (1996). Tribology of contact/near-contact recording for ultrahigh density magnetic storage, ASME Tribology, Vol. 6, pp. 33-41. ISSN 0022-2305

Yamamoto, T.; Toyoguchi, T. \& Honda, F. (2000). Ultrathin amorphous C:H overcoats by PCVD on thin film media, IEEE Trans. Magn., Vol. 36, pp. 115-119. ISSN 0018-9464

Yamamoto, T.; Hyodo, H.; Tsuchitani, S. \& Kaneko, R. (2003). Ultrathin amorphous carbon overcoats by filtered cathodic arc deposition, IEEE Trans. on Magn., Vol. 39, pp. 2201-2204. ISSN 0018-9464 


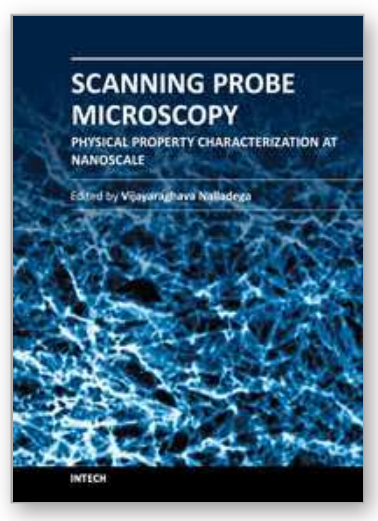

\section{Scanning Probe Microscopy-Physical Property Characterization at Nanoscale}

Edited by Dr. Vijay Nalladega

ISBN 978-953-51-0576-3

Hard cover, 242 pages

Publisher InTech

Published online 27, April, 2012

Published in print edition April, 2012

Scanning probe microscopy (SPM) is one of the key enabling tools for the advancement for nanotechnology with applications in many interdisciplinary research areas. This book presents selected original research works on the application of scanning probe microscopy techniques for the characterization of physical properties of different materials at the nanoscale. The topics in the book range from surface morphology analysis of thin film structures, oxide thin layers and superconducting structures, novel scanning probe microscopy techniques for characterization of mechanical and electrical properties, evaluation of mechanical and tribological properties of hybrid coatings and thin films. The variety of topics chosen for the book underlines the strong interdisciplinary nature of the research work in the field of scanning probe microscopy.

\section{How to reference}

In order to correctly reference this scholarly work, feel free to copy and paste the following:

Shojiro Miyake and Mei Wang (2012). Nanomechanical Evaluation of Ultrathin Lubricant Films on Magnetic Disks by Atomic Force Microscopy, Scanning Probe Microscopy-Physical Property Characterization at Nanoscale, Dr. Vijay Nalladega (Ed.), ISBN: 978-953-51-0576-3, InTech, Available from: http://www.intechopen.com/books/scanning-probe-microscopy-physical-property-characterization-atnanoscale/nanomechanical-evaluation-of-ultrathin-lubricant-films-on-magnetic-disks-by-atomic-forcemicroscopy

\section{INTECH}

open science | open minds

\section{InTech Europe}

University Campus STeP Ri

Slavka Krautzeka 83/A

51000 Rijeka, Croatia

Phone: +385 (51) 770447

Fax: +385 (51) 686166

www.intechopen.com

\section{InTech China}

Unit 405, Office Block, Hotel Equatorial Shanghai

No.65, Yan An Road (West), Shanghai, 200040, China

中国上海市延安西路65号上海国际贵都大饭店办公楼 405 单元

Phone: +86-21-62489820

Fax: $+86-21-62489821$ 
(C) 2012 The Author(s). Licensee IntechOpen. This is an open access article distributed under the terms of the Creative Commons Attribution 3.0 License, which permits unrestricted use, distribution, and reproduction in any medium, provided the original work is properly cited. 